\title{
34. MAGNETIC PROPERTIES OF DSDP LEG 55 BASALTS
}

\author{
Masaru Kono, Geophysical Institute, University of Tokyo
}

\section{INTRODUCTION}

Leg 55 of the Deep Sea Drilling Project (DSDP) was devoted to drilling the crustal layers of four of the Emperor Seamounts. Volcanic basement was reached on Ōjin, Nintoku, and Suiko. The volcanic rocks obtained are alkalic basalts and tholeiites similar to rocks of the Hawaiian Islands (Kirkpatrick et al., this volume), and many lines of evidence show that these basalts erupted and accumulated subaerially, in contrast to the ordinary ocean floor basalts which originate from midoceanic ridges. The basalts of Ōjin, Nintoku, and Suiko are dated by $\mathrm{K}-\mathrm{Ar}$ and ${ }^{40} \mathrm{Ar}-{ }^{39} \mathrm{Ar}$ methods at $55.2,56.2$, and 64.7 m.y., respectively (Dalrymple et al., this volume), in substantial agreement with the hypothesis of a hot-spot origin of the Emperor Seamounts (Morgan, 1971, 1972). Paleomagnetic data also suggest that the seamounts moved northward since their formation (Kono, this volume).

Up to the present, magnetic properties of seamount basalts have been inferred mostly from studies of dredged samples (Lowrie, 1974, 1977). A small number of samples had already been obtained from seamounts by drilling (Midway Island and Meiji Seamount), but the Leg 55 basalts constitute the most extensively sampled in-situ rocks of seamount volcanic basement presently available. In particular, Hole $433 \mathrm{C}$ on Suiko Seamount penetrated 390 meters of basaltic layer, and yielded 250 meters of cores containing both alkalic basalts and tholeiites and composed of more than 100 flow units. The main objective of this chapter is to present the results of measurements of various magnetic properties and to compare the seamount basalts with the sea floor basalts in terms of magnetic characteristics. In sea floor basalts, low-temperature oxidation of titanomagnetites occurs almost universally (e.g., Hall and Ryall, 1977). On the basis of magnetic studies on dredged samples (Ozima et al., 1968), the same situation has been suspected to prevail in seamounts. The present study, however, clearly shows that low-temperature oxidation is not an important process in these seamount basalts. Instead, almost all of my samples show evidence of high-temperature oxidation of titanomagnetites, which should have occurred when the lava flows first cooled after eruption (Kono, Clague, and Larson, this volume). The data presented here are useful in assessing the reliability of paleomagnetic data obtained from seamount samples, in modeling seamount magnetic anomalies, and in comparing magnetic properties of seamount basalts with those of ocean floor basalts.

\section{EXPERIMENTAL METHODS}

Minicore specimens of $2.5 \mathrm{~cm}$ diameter and $2.3 \mathrm{~cm}$ long were used for measurement of the intensity of natural remanent magnetization (NRM), median demagnetizing field (MDF), and initial susceptibility. Alternating-field (AF) demagnetization was carried out using a Schonstedt AC demagnetizer, and the remanences were measured on Digico and Schonstedt spinner magnetometers. Initial susceptibility was measured using a Bison 3101 susceptibility system, and appropriate corrections for sample volume were applied.

Strong-field measurements were done using both a Princeton vibrating sample magnetometer (VSM) and a Hirone-type magnetic balance. Hysteresis properties at room temperature were measured on cylindrical specimens $2.5 \mathrm{~mm}$ diameter and 3 to $4 \mathrm{~mm}$ long, using a VSM with a maximum magnetic field of $12 \mathrm{kOe}$. (1 Oe is equal to $79.6 \mathrm{~A}$ in S.I. units). Only the $1 \mathrm{emu}$ and $0.1 \mathrm{emu}$ ranges were used in VSM measurements, so linearity is good to less than 1 per cent. The system was calibrated by using small chips of nickel as standards. Saturation magnetization $\left(J_{s}\right)$ was obtained by a linear regression of $J$ (magnetization) against $\mathrm{l} / \mathrm{H}$ (magnetic field) for field values of $7,8,9,10,11$, and $12 \mathrm{kOe}$. This procedure was chosen because in most samples, owing to the presence of superparamagnetic components (see later discussion), $J$ is linear to $1 / H$ in this field range, whereas it is nonlinear in weaker fields. Saturation remanence was determined by reducing the magnetic field from $12 \mathrm{kOe}$ to zero. Coercive force was calculated by fitting a quadratic curve to magnetizations at 500,0 , and -200 Oe.

Thermomagnetic analyses were carried out using a magnetic balance in a vacuum of $10^{-4}$ to $10^{-5}$ Torr (1 Torr $=133 \mathrm{~Pa}$ ) and in a constant magnetic field of 5 kOe. Chips of 40 - to $100-\mathrm{mg}$ samples were heated and cooled in a quartz basket at a constant rate of $600^{\circ}$ $\mathrm{C} /$ hour. A platinel thermocouple was placed just beside the sample, inside the basket. Curie temperatures of $500^{\circ} \mathrm{C}$ and higher were determined with errors of less than a few degrees. For lower Curie temperatures, the errors were greater, because humps appear in such $J_{s^{-}}-T$ diagrams (see Figure 1), but are probably less than $30^{\circ} \mathrm{C}$ for most samples.

For selected samples, lattice parameters of magnetic minerals were determined using a JEOL X-ray diffractometer with iron target. Diffraction angles were calibrated using diffraction patterns of silicon powder. Oxidation state of ferromagnetic minerals was deter- 

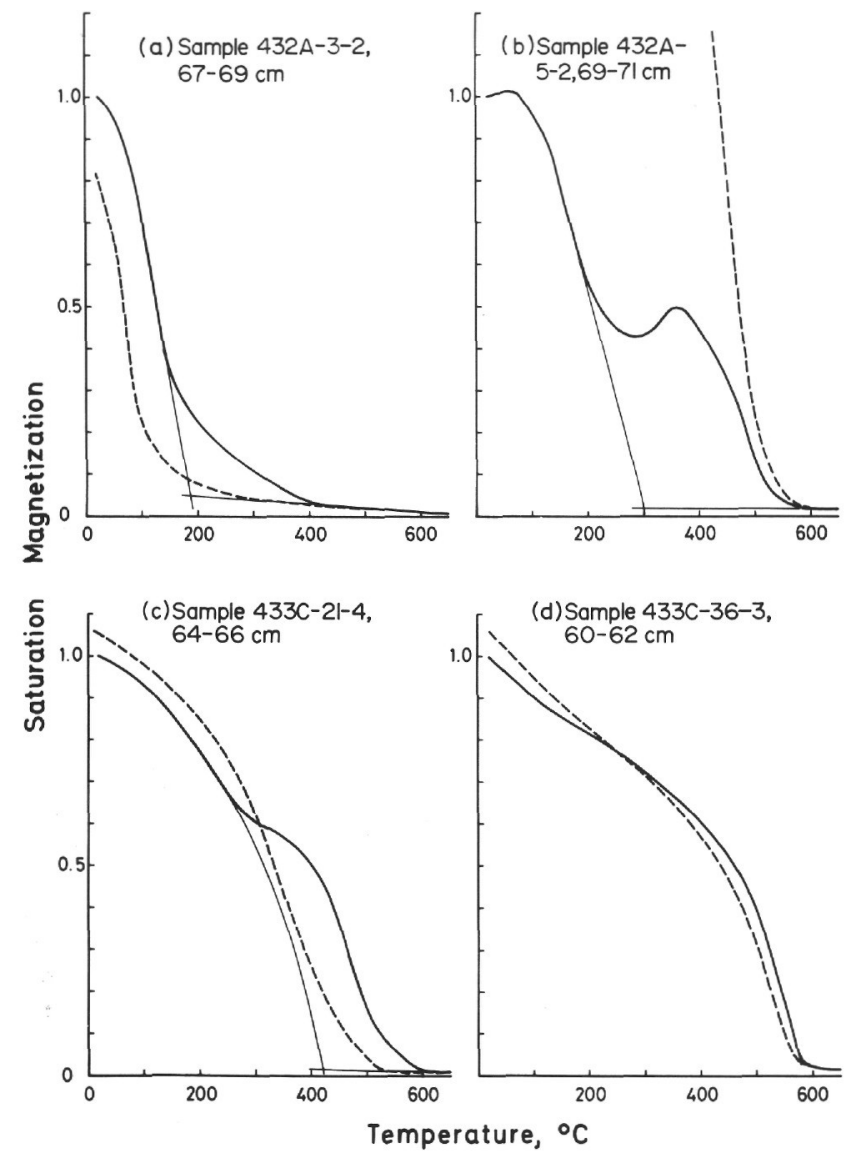

Figure 1. Thermomagnetic curves obtained in a magnetic field of $5 \mathrm{kOe}$ and a vacuum of $<10^{-4}$ Torr. Magnetization is normalized by the room temperature value. Extrapolation of curves shows the method of determining Curie points. (a) NO sample which shows little trace of either high-or low-temperature oxidation. (b), (c) LT samples with varying degrees of titanomaghemitization. Note the large ambiguity in determination of $\mathrm{T}_{c}$ (d) HT sample with nearly reversible $\mathrm{J}_{\mathrm{s}}-\mathrm{T}$ curve.

mined from $J_{s}-T$ curves and optical microscope analysis (Kono, Clague, and Larson, this volume).

\section{RESULTS}

NRM intensity $\left(J_{n}\right)$, initial susceptibility $(\chi)$, median demagnetizing field (MDF), and Königsberger ratio $\left(Q_{n}\right.$ $=J_{n}(\chi H)$ of all the samples are listed in site reports (this volume). Table 1 is a summary of other magnetic properties measured on 99 samples. The magnetic properties listed in Table 1 are saturation magnetization $J_{s}$, saturation remanence $J_{r}$, coercive force $H_{c}$, Curie temperature $T_{c}$, and the ratios $J_{r} / J_{s}, J(5 \mathrm{kOe}) / J_{s}, J i / J f$. Saturation magnetization is listed in three columns; $J_{s}(\mathrm{~V})$ is determined by VSM, $J_{s}(\mathrm{~B})$ is determined by the magnetic balance, with correction for undersaturation by the factor $J(5 \mathrm{kOe}) / J_{s}$, where available, and $J_{s}$ is the average of the two. The ratio $J^{i} / J^{f}$ indicates the relative magnitude of the original $J_{s}$ compared with the $J_{s}$ after the sample was heated to and cooled from $700^{\circ} \mathrm{C}$ in vacuum in thermomagnetic analysis. Also listed in this table are flow unit number, depth sub-bottom, rock type (tholeiite $\mathrm{T}$, alkalic basalt $\mathrm{A}$, or sandstone derived from alkalic basalt S), and the oxidation type of titanomagnetites. Oxidation types are classified as not oxidized (NO), high-temperature oxidation (HT), and lowtemperature oxidation (LT), according to the results of thermomagnetic analyses, supplemented by reflection microscopic observation (Kono, Clague, and Larson, this volume).

Averages (both arithmetic and geometric) and standard deviations of individual magnetic properties of different rock types as well as individual holes are given in Table 2, and the distributions of values are shown in Figure 2. Individual magnetic properties are discussed separately below.

\section{NRM Intensity $J_{n}$}

NRM intensity in the Leg 55 basalts ranges between 0.14 and $31.5 \times 10^{-3} \mathrm{emu} / \mathrm{cm}^{3}\left(1 \mathrm{emu} / \mathrm{cm}^{3}=1\right.$ Gauss $\left.=10^{3} \mathrm{~A} / \mathrm{m}\right)$, with an arithmetic mean of $5.01 \times 10^{-3}$ $\mathrm{emu} / \mathrm{cm}^{3}$ and a geometric mean of $3.66 \times 10^{-3}$ $\mathrm{emu} / \mathrm{cm}^{3}$. The distribution of individual values is nearly log-normal (Figure 2a). Use of the geometric mean (GM) is mathematically appropriate for such a distribution, but the arithmetic mean (AM) is preferable for practical purposes. The range and the shape of this distribution are quite similar to those of DSDP and dredged samples compiled by Lowrie $(1974,1977)$. The DSDP samples in Lowrie's compilation are from sea floor of various ages, and represent some average of mid-oceanic ridge-type basalts. The dredged samples, on the other hand, comprise sea floor basalts obtained mostly near the mid-oceanic ridges, as well as basalts collected from seamounts. However, the mean NRM intensity of Leg 55 basalts is more similar to that of Lowrie's (1977) DSDP basalts $\left(\mathrm{AM}=4.04 \times 10^{-3}\right.$ $\left.\mathrm{emu} / \mathrm{cm}^{3}\right)$ than to that of dredged basalts $(\mathrm{AM}=14.4$ $\left.\times 10^{-3} \mathrm{emu} / \mathrm{cm}^{3}\right)$.

The average NRM intensities of alkalic basalts and tholeiites differ slightly, but the difference is not significant (Figure $2 \mathrm{a}$ and Table 2). The volcaniclastic sandstone samples of Holes $430 \mathrm{~A}$ and $432 \mathrm{C}$ were obtained just above the basaltic basement layers in each hole. The chemical composition and physical properties of these samples are quite similar to those of the alkalic basalts underlying the sandstone layers (Kirkpatrick et al., this volume; Kono, Hamano, and Morgan, this volume). Magnetic properties of the sandstone are also similar to those of alkalic basalts (Figure 2). Accordingly, they can be considered as crushed and redeposited alkalic basalts. An order of magnitude difference in $J_{n}$ can be interpreted as the result of difference in the efficiency of acquisition of TRM and depositional remanent magnetization (DRM) and also the difference in concentration of magnetic minerals (as shown by $J_{s}$ and $\chi$ ).

Some authors have suggested that $J_{n}$ in submarine basalts may decrease as a result of maghemitization with 
TABLE

Rock Magnetic Results, DSDP Leg 55

\begin{tabular}{|c|c|c|c|c|c|c|c|c|c|c|c|c|c|}
\hline $\begin{array}{l}\text { Hole/Core/Sect/Int } \\
(\mathrm{cm})\end{array}$ & Unit & Type & Oxid & $\begin{array}{l}\text { Depth } \\
\text { (m) }\end{array}$ & $\begin{array}{c}J_{S}(\mathrm{~V}) \\
(\mathrm{emu} / \mathrm{g})\end{array}$ & $\begin{array}{c}J_{S}(\mathrm{~B}) \\
(\mathrm{emu} / \mathrm{g})\end{array}$ & $\begin{array}{c}J_{S} \\
(\mathrm{emu} / \mathrm{g})\end{array}$ & $\begin{array}{c}J_{r} \\
(\mathrm{emu} / \mathrm{g})\end{array}$ & $\begin{array}{l}H_{C} \\
(\mathrm{Oe})\end{array}$ & $J_{r} / J_{S}$ & $\begin{array}{c}J(5 \mathrm{kOe}) / \\
J_{S}\end{array}$ & $\begin{array}{c}T_{c} \\
\left({ }^{\circ} \mathrm{C}\right)\end{array}$ & $J i / J f$ \\
\hline $430 A-5-2,30-32$ & 1 & (A) & HT & 68.37 & 1.709 & 1.851 & 1.780 & 0.220 & 107 & 0.129 & 0.859 & 520 & 0.938 \\
\hline $5-3,107-109$ & 1 & (A) & HT & 70.66 & 1.662 & 1.808 & 1.735 & 0.164 & 105 & 0.099 & 0.845 & 503 & 0.947 \\
\hline $5-5,44-46$ & 2 & (A) & HT & 73.15 & 1.714 & 1.949 & 1.831 & 0.276 & 223 & 0.161 & 0.854 & 575 & 0.878 \\
\hline $5-5,103-105$ & 2 & (A) & $\mathrm{HT}$ & 73.75 & 1.868 & 1.975 & 1.921 & 0.298 & 243 & 0.160 & 0.855 & 583 & 0.968 \\
\hline $6-1,67-69$ & 2 & (A) & HT & 76.60 & 1.653 & 1.927 & 1.790 & 0.215 & 213 & 0.130 & 0.848 & 575 & 0.927 \\
\hline $6-1,88-90$ & 2 & (A) & HT & 76.79 & 1.632 & 1.724 & 1.678 & 0.184 & 205 & 0.113 & 0.846 & 576 & 0.983 \\
\hline $6-2,54-56$ & 3 & (A) & HT & 77.61 & 1.892 & 1.819 & 1.856 & 0.377 & 278 & 0.199 & 0.842 & 582 & 0.952 \\
\hline $6-2,122-124$ & 3 & (A) & HT & 78.19 & 1.879 & 2.164 & 2.021 & 0.265 & 223 & 0.141 & 0.847 & 576 & 0.970 \\
\hline $6-4,15-17$ & 4 & (A) & HT & 79.87 & 1.956 & 2.295 & 2.126 & 0.306 & 254 & 0.156 & 0.846 & 577 & 0.995 \\
\hline $432 \mathrm{~A}-2-1,33-35$ & SS & $(\mathrm{S})$ & LT & 41.81 & 1.539 & 1.266 & 1.403 & 0.266 & 144 & 0.173 & 0.878 & 374 & 0.733 \\
\hline $2-1,74-76$ & 1 & (A) & LT & 42.13 & 2.126 & 2.517 & 2.322 & 0.634 & 316 & 0.298 & 0.849 & 373 & 0.752 \\
\hline $2-1,107-109$ & 1 & (A) & LT & 42.46 & 1.879 & 2.756 & 2.318 & 0.529 & 275 & 0.281 & 0.866 & 364 & 0.743 \\
\hline $2-2,23-25$ & 2 & (A) & $\mathrm{HT}$ & 42.90 & 3.039 & 3.374 & 3.206 & 0.564 & 271 & 0.186 & 0.886 & 575 & 1.029 \\
\hline $2-2,72-74$ & 2 & (A) & HT & 43.34 & 2.650 & 2.579 & 2.614 & 0.546 & 288 & 0.206 & 0.884 & 572 & 1.059 \\
\hline $2-3,12-14$ & 2 & (A) & LT & 44.13 & 1.543 & 1.495 & 1.519 & 0.451 & 296 & 0.292 & 0.849 & 457 & 1.114 \\
\hline $2-3,21-23$ & 2 & (A) & & 44.22 & 1.045 & & 1.045 & 0.249 & 157 & 0.239 & 0.817 & & \\
\hline $3-2,67-69$ & 3 & (A) & No & 56.77 & 2.541 & 2.700 & 2.620 & 0.382 & 73 & 0.151 & 0.883 & 187 & 1.226 \\
\hline $4-1,64-66$ & 3 & (A) & $\mathrm{HT}$ & 65.08 & 4.170 & 4.042 & 4.106 & 0.668 & 160 & 0.160 & 0.918 & 550 & 0.967 \\
\hline $4-1,73-75$ & 3 & (A) & HT & 65.17 & 3.667 & 2.687 & 3.177 & 0.516 & 177 & 0.141 & 0.893 & 579 & 1.011 \\
\hline $4-1,120-122$ & 3 & (A) & LT & 65.59 & 3.643 & 2.833 & 3.238 & 0.588 & 203 & 0.162 & 0.896 & 391 & 0.653 \\
\hline $4-2,80-82$ & 3 & (A) & HT & 66.60 & 2.897 & 2.125 & 2.511 & 0.650 & 188 & 0.224 & 0.895 & 577 & 1.080 \\
\hline $5-2,69-71$ & 3 & (A) & LT & 73.04 & 1.568 & 1.736 & 1.652 & 0.346 & 120 & 0.220 & 0.786 & 299 & 0.324 \\
\hline $33 \mathrm{~A}-20-2,2-4$ & 1 & (A) & HT & 165.04 & 4.105 & 4.721 & 4.413 & 0.790 & 243 & 0.192 & 0.89 & 581 & 1.012 \\
\hline $20-2,14-16$ & 1 & (A) & $\mathrm{HT}$ & 5.16 & 4.0 & 3.1 & 3.623 & & 194 & & 0. & 580 & 0.944 \\
\hline $20-2,24-26$ & 1 & (A) & HT & 165 & & 3.8 & & & 191 & 0.183 & 0.900 & 580 & 0.907 \\
\hline $433 \mathrm{C}-10-3,92-94$ & 4 & (T) & HT & 207 & 1.2 & & 1.8 & 0 & 165 & 0.244 & 0.888 & 569 & 1.008 \\
\hline $10-3,145-147$ & 4 & (T) & $\mathrm{HT}$ & 208.07 & 1.996 & 2.404 & 2.200 & 0.466 & 161 & 0.233 & 0.881 & 569 & 0.844 \\
\hline $10-4,69-71$ & 4 & (T) & $\mathrm{HT}$ & 208.76 & 1.125 & 2.034 & 1.580 & 0.197 & 120 & 0.175 & 0.854 & 572 & 0.810 \\
\hline $10-6,38-40$ & 5 & (T) & $\mathrm{HT}$ & 211.09 & 0.803 & 0.864 & 0.833 & 0.058 & 67 & 0.072 & 0.687 & 574 & 0.859 \\
\hline $11-1,139-141$ & 6 & (T) & HT & 215.12 & 1.114 & 1.237 & 1.175 & 0.163 & 131 & 0.146 & 0.813 & 573 & 0.922 \\
\hline $11-3,84-86$ & 7 & (T) & $\mathrm{HT}$ & 217.19 & 0.727 & 1.058 & 0.892 & 0.064 & 156 & 0.088 & 0.647 & 579 & 0.866 \\
\hline $11-3,112-114$ & 7 & (T) & $\mathrm{HT}$ & 217.47 & 0.768 & 0.545 & 0.656 & 0.078 & 163 & 0.101 & 0.664 & 582 & 0.821 \\
\hline $11-5,36-38$ & 8 & (T) & HT & 218.92 & 1.565 & 1.977 & 1.771 & 0.267 & 127 & 0.171 & 0.845 & 539 & 1.013 \\
\hline $12-1,109-111$ & 9 & (T) & HT & 224.41 & 0.636 & 0.973 & 0.805 & 0.103 & 111 & 0.162 & 0.736 & 554 & 0.811 \\
\hline $12-3,5-7$ & 9 & (T) & LT & 226.21 & 0.840 & 0.946 & 0.893 & 0.116 & 82 & 0.138 & 0.750 & 264 & 0.793 \\
\hline $13-1,125-127$ & 10 & (T) & LT & 231.18 & 1.045 & 0.936 & 0.991 & 0.149 & 78 & 0.143 & 0.800 & 242 & 0.749 \\
\hline $13-2,103-105$ & 10 & (T) & $\mathrm{HT}$ & 232.44 & 0.679 & 0.915 & 0.797 & 0.055 & 76 & 0.080 & 0.670 & 543 & 0.879 \\
\hline $14-2,37-39$ & $11 \mathrm{~A}$ & (T) & HT & 234.84 & 0.915 & 1.215 & 1.065 & 0.119 & 146 & 0.131 & 0.746 & 574 & 0.968 \\
\hline $15-1,17-19$ & $11 \mathrm{~B}$ & (T) & LT & 242.65 & 1.042 & 1.277 & 1.159 & 0.180 & 115 & 0.173 & 0.796 & 376 & 0.904 \\
\hline $15-4,48-50$ & 12 & (T) & HT & 246.22 & 4.016 & 3.541 & 3.778 & 0.300 & 75 & 0.075 & 0.922 & 551 & 0.966 \\
\hline $15-4,84-86$ & 12 & (T) & $\mathrm{HT}$ & 246.50 & 4.009 & 4.167 & 4.088 & 0.365 & 98 & 0.091 & 0.921 & 539 & 1.110 \\
\hline $15-5,72-74$ & 13 & (T) & HT & 247.66 & 1.312 & 1.336 & 1.324 & 0.159 & 134 & 0.121 & 0.855 & 583 & 0.798 \\
\hline $16-1,80-82$ & 13 & (T) & LT & 252.74 & 2.081 & 2.034 & 2.058 & 0.292 & 104 & 0.140 & 0.851 & 246 & 0.734 \\
\hline $19-2,9-11$ & 14 & (T) & $\mathrm{HT}$ & 262.95 & 0.568 & 0.858 & 0.713 & 0.051 & 218 & 0.090 & 0.515 & 576 & 0.714 \\
\hline $19-2,40-42$ & 14 & (T) & $\mathrm{HT}$ & 263.25 & 0.413 & 0.490 & 0.452 & 0.025 & 135 & 0.061 & 0.453 & 577 & 0.796 \\
\hline $19-2,64-66$ & 14 & (T) & HT & 263.49 & 0.534 & 0.497 & 0.516 & 0.067 & 292 & 0.125 & 0.547 & 546 & 0.520 \\
\hline $19-3,74-76$ & $15 \mathrm{~A}$ & (T) & HT & 264.88 & 1.083 & 1.114 & 1.098 & 0.226 & 237 & 0.209 & 0.766 & 574 & 0.930 \\
\hline $20-1,103-105$ & $15 \mathrm{~B}$ & (T) & LT & 270.39 & 0.840 & 0.920 & 0.880 & 0.139 & 120 & 0.166 & 0.709 & 397 & 0.716 \\
\hline $20-2,20-22$ & $15 \mathrm{~B}$ & (T) & LT & 270.90 & 0.891 & 0.996 & 0.944 & 0.132 & 124 & 0.149 & 0.695 & 334 & 0.753 \\
\hline $20-2,35-37$ & $15 \mathrm{~B}$ & (T) & LT & 271.03 & 0.682 & 0.991 & 0.837 & 0.100 & 142 & 0.147 & 0.6 & 367 & 0.721 \\
\hline $21-1,128-130$ & 16 & (T) & $\mathrm{HT}$ & 280.06 & 2.296 & 3.127 & 2.712 & 0.222 & 116 & 0.097 & 0.873 & 520 & 1.116 \\
\hline $21-3,7-9$ & 17 & (T) & HT & 281.35 & 1.469 & 1.391 & 1.430 & 0.204 & 153 & 0.139 & 0.829 & 532 & 0.938 \\
\hline $21-4,64-66$ & 17 & (T) & LT & 283.01 & 2.282 & 2.496 & 2.389 & 0.351 & 158 & 0.154 & 0.892 & 421 & 0.948 \\
\hline $21-4,101-103$ & 17 & (T) & LT & 283.29 & 2.048 & 2.269 & 2.158 & 0.267 & 126 & 0.130 & 0.884 & 375 & 0.999 \\
\hline $22-1,104-106$ & 18 & (T) & $\mathrm{HT}$ & 289.26 & 1.858 & 1.900 & 1.879 & 0.239 & 156 & 0.129 & 0.860 & 537 & 0.962 \\
\hline $23-4,99-101$ & 19 & (T) & $\mathrm{HT}$ & 302.75 & & 1.106 & 1.106 & & & & & 581 & 0.976 \\
\hline $25-2,7-9$ & 20 & (T) & $\mathrm{HT}$ & 318.49 & 0.530 & 0.646 & 0.588 & 0.066 & 399 & 0.125 & 0.547 & 574 & 0.591 \\
\hline $25-2,27-29$ & 20 & (T) & $\mathrm{HT}$ & 318.69 & 0.495 & 0.763 & 0.629 & 0.047 & 306 & 0.096 & 0.532 & 570 & 0.702 \\
\hline $25-2,54-56$ & 20 & (T) & $\mathrm{HT}$ & 318.96 & 0.579 & 0.726 & 0.653 & 0.081 & 310 & 0.141 & 0.608 & 561 & 0.872 \\
\hline $25-5,103-105$ & 21 & (T) & $\mathrm{HT}$ & 323.58 & 1.261 & 1.334 & 1.297 & 0.184 & 235 & 0.146 & 0.799 & 576 & 0.973 \\
\hline $26-5,94-96$ & 22 & (T) & HT & 333.07 & 0.570 & 0.697 & 0.634 & 0.073 & 390 & 0.129 & 0.545 & 572 & 0.768 \\
\hline $26-6,49-51$ & 23 & (T) & HT & 333.85 & 1.019 & 1.307 & 1.163 & 0.162 & 206 & 0.159 & 0.786 & 553 & 0.847 \\
\hline $26-6,129-131$ & 23 & (T) & HT & 334.66 & 0.619 & 0.727 & 0.673 & 0.063 & 155 & 0.102 & 0.627 & 535 & 0.979 \\
\hline $27-5,41-43$ & 24 & (T) & HT & 341.71 & 0.613 & 1.184 & 0.899 & 0.043 & 99 & 0.071 & 0.629 & 541 & 0.905 \\
\hline
\end{tabular}


TABLE 1 - Continued

\begin{tabular}{|c|c|c|c|c|c|c|c|c|c|c|c|c|c|}
\hline $\begin{array}{l}\text { Hole/Core/Sect/Int } \\
\text { (cm) }\end{array}$ & Unit & Type & Oxid & $\begin{array}{l}\text { Depth } \\
\text { (m) }\end{array}$ & $\begin{array}{c}J_{S}(\mathrm{~V}) \\
(\mathrm{emu} / \mathrm{g})\end{array}$ & $\begin{array}{c}J_{S}(\mathrm{~B}) \\
(\mathrm{emu} / \mathrm{g})\end{array}$ & $\begin{array}{c}J_{S} \\
(\mathrm{emu} / \mathrm{g})\end{array}$ & $\begin{array}{c}J_{r} \\
(\mathrm{emu} / \mathrm{g})\end{array}$ & $\begin{array}{l}H_{C} \\
\text { (Oe) }\end{array}$ & $J_{r} / J_{S}$ & $\begin{array}{c}J(5 \mathrm{kOe}) / \\
J_{S}\end{array}$ & $\begin{array}{l}T_{C} \\
\left({ }^{\circ} \mathrm{C}\right)\end{array}$ & $J^{i} / J^{f}$ \\
\hline $33 \mathrm{C}-28-4,121-123$ & $26 \mathrm{~A}$ & (T) & HT & 350.66 & 0.823 & 0.918 & 0.871 & 0.125 & 372 & 0.151 & 0.675 & 580 & 1.013 \\
\hline $29-2,115-117$ & $26 \mathrm{~B}$ & (T) & $\mathrm{LT}$ & 357.14 & 1.419 & 1.613 & 1.516 & 0.188 & 88 & 0.133 & 0.844 & 492 & 0.535 \\
\hline $31-4,83-85$ & $28 \mathrm{~A}$ & (T) & HT & 378.42 & 0.745 & 0.641 & 0.693 & 0.075 & 100 & 0.101 & 0.757 & 562 & 0.951 \\
\hline $32-1,38-40$ & $28 \mathrm{~B}$ & (T) & HT & 383.81 & 0.506 & 0.626 & 0.566 & 0.035 & 137 & 0.070 & 0.576 & 582 & 0.887 \\
\hline $32-1,112-114$ & $28 \mathrm{~B}$ & (T) & HT & 384.55 & 0.648 & 0.818 & 0.733 & 0.047 & 115 & 0.073 & 0.577 & 558 & 0.494 \\
\hline $35-1,112-114$ & 35 & (T) & HT & 413.13 & 1.140 & 1.748 & 1.444 & 0.099 & 107 & 0.086 & 0.792 & 546 & 1.065 \\
\hline $35-6,48-50$ & 35 & (T) & HT & 419.78 & 1.476 & 1.162 & 1.319 & 0.148 & 124 & 0.100 & 0.818 & 557 & 0.988 \\
\hline $35-6,121-123$ & 36 & (T) & HT & 420.12 & 0.413 & 0.515 & 0.464 & 0.026 & 82 & 0.062 & 0.584 & 573 & 0.603 \\
\hline $35-7,116-118$ & 36 & (T) & HT & 421.74 & 0.618 & 0.760 & 0.689 & 0.079 & 291 & 0.128 & 0.630 & 583 & 0.842 \\
\hline $36-1,45-47$ & 36 & (T) & HT & 421.96 & 0.781 & 1.004 & 0.892 & 0.128 & 337 & 0.163 & 0.655 & 576 & 0.979 \\
\hline $36-1,105-107$ & 37 & (T) & HT & 422.50 & 1.275 & 1.416 & 1.346 & 0.209 & 186 & 0.164 & 0.833 & 577 & 1.009 \\
\hline $36-3,60-62$ & 38 & (T) & HT & 424.81 & 1.187 & 1.533 & 1.360 & 0.156 & 136 & 0.131 & 0.767 & 577 & 0.945 \\
\hline $36-4,56-58$ & 39 & (T) & HT & 426.24 & 0.618 & 0.949 & 0.784 & 0.001 & 1 & 0.001 & 0.552 & 528 & 0.951 \\
\hline $36-5,29-31$ & 40 & (T) & HT & 427.44 & & 0.423 & 0.423 & & & & & 540 & 0.977 \\
\hline $37-3,74-76$ & 44 & (T) & HT & 434.21 & 0.867 & 1.240 & 1.054 & 0.094 & 96 & 0.108 & 0.743 & 534 & 1.010 \\
\hline $38-1,57-59$ & 45 & (T) & HT & 441.08 & 0.512 & 0.662 & 0.587 & 0.002 & 11 & 0.004 & 0.430 & 577 & 0.674 \\
\hline $38-5,119-121$ & 47 & (T) & LT & 447.40 & 0.503 & 0.705 & 0.604 & 0.010 & 24 & 0.019 & 0.511 & 364 & 0.930 \\
\hline $39-5,96-98$ & 48 & (T) & HT & 456.44 & 0.510 & 0.582 & 0.546 & 0.008 & 43 & 0.016 & 0.465 & 581 & 0.732 \\
\hline $39-6,78-80$ & 48 & (T) & HT & 457.75 & 0.603 & 0.537 & 0.570 & 0.020 & 55 & 0.034 & 0.566 & 573 & 0.680 \\
\hline $41-1,51-53$ & $51 \mathrm{~B}$ & (T) & HT & 469.52 & 1.095 & 1.389 & 1.242 & 0.117 & 137 & 0.107 & 0.740 & 573 & 0.972 \\
\hline $42-1,68-70$ & 52 & (T) & & 479.19 & 0.981 & & 0.981 & 0.076 & 119 & 0.078 & 0.719 & & \\
\hline $42-2,136-138$ & 53 & (T) & HT & 481.12 & 1.253 & 1.422 & 1.338 & 0.208 & 225 & 0.166 & 0.801 & 573 & 1.016 \\
\hline $42-5,134-136$ & 54 & (T) & LT & 485.01 & 1.214 & 1.362 & 1.288 & 0.200 & 170 & 0.165 & 0.775 & 425 & 0.865 \\
\hline $43-1,33-35$ & 54 & (T) & HT & 488.34 & 0.960 & 1.348 & 1.154 & 0.081 & 121 & 0.084 & 0.740 & 578 & 1.015 \\
\hline $44-1,41-43$ & 56 & (T) & HT & 497.92 & 1.353 & 1.478 & 1.416 & 0.200 & 117 & 0.148 & 0.800 & 553 & 1.040 \\
\hline $44-4,108-110$ & 58 & (T) & HT & 502.68 & 1.185 & 1.332 & 1.258 & 0.227 & 216 & 0.192 & 0.763 & 553 & 1.021 \\
\hline $45-2,45-47$ & 59 & (T) & HT & 508.91 & 0.997 & 1.402 & 1.200 & 0.187 & 220 & 0.188 & 0.719 & 555 & 0.946 \\
\hline $45-5,51-53$ & 60 & (T) & LT & 513.25 & 1.573 & 1.919 & 1.746 & 0.219 & 89 & 0.139 & 0.830 & 371 & 0.783 \\
\hline $45-6,43-45$ & 60 & (T) & LT & 514.59 & 1.185 & 0.979 & 1.082 & 0.152 & 79 & 0.128 & 0.817 & 431 & 0.562 \\
\hline $46-3,54-56$ & 62 & (T) & HT & 519.95 & 1.043 & 0.990 & 1.016 & 0.114 & 146 & 0.109 & 0.769 & 579 & 0.888 \\
\hline $47-1,26-28$ & 63 & (T) & HT & 526.24 & 1.164 & 1.453 & 1.309 & 0.187 & 199 & 0.161 & 0.756 & 579 & 1.000 \\
\hline $47-5,25-27$ & 64 & (A) & LT & 531.94 & 1.298 & 1.482 & 1.390 & 0.254 & 99 & 0.196 & 0.847 & 472 & 0.914 \\
\hline $48-3,30-$ & 64 & (A) & HT & 538.76 & 0.879 & 1.320 & 1.100 & 0.061 & 90 & 0.070 & 0.656 & 575 & 1.001 \\
\hline $49-1,142-144$ & 66 & (T) & HT & 546.38 & 0.701 & 1.0 & 0.888 & 0.099 & 206 & 0.141 & 0.667 & 577 & 1.048 \\
\hline $49-2,50-52$ & 66 & $(\mathrm{~T})$ & HT & 546.95 & 0.889 & 0.858 & 0.873 & 0.148 & 210 & 0.166 & 0.696 & 575 & 0.926 \\
\hline
\end{tabular}

TABLE 2

Average Magnetic Properties of Individual Groups of Leg 55 Basalt Samples

\begin{tabular}{|c|c|c|c|c|c|c|c|}
\hline $\begin{array}{l}\text { Magnetic } \\
\text { Properties }\end{array}$ & $\begin{array}{l}\text { Volcaniclastic } \\
\text { Sandstone }\end{array}$ & Alkalic Basalt & Tholeiite & $\begin{array}{l}\text { Site } 430 \\
(\bar{O} \text { jin })\end{array}$ & $\begin{array}{c}\text { Site } 432 \\
\text { (Nintoku) }\end{array}$ & $\begin{array}{l}\text { Site } 433 \\
\text { (Suiko) }\end{array}$ & Total \\
\hline$J_{n}\left(10^{-3} \mathrm{emu} / \mathrm{cm}^{3}\right)$ & $\begin{array}{l}0.40 \pm 0.05(7) \\
0.40\end{array}$ & $\begin{array}{l}6.09 \pm 3.93(84) \\
5.14\end{array}$ & $\begin{array}{l}4.85 \pm 4.60(361) \\
3.54\end{array}$ & $\begin{array}{l}4.72 \pm 3.75(31) \\
3.25\end{array}$ & $\begin{array}{l}5.58 \pm 3.10(32) \\
4.30\end{array}$ & $\begin{array}{l}4.99 \pm 4.66(389) \\
3.65\end{array}$ & $\begin{array}{l}5.01 \pm 4.51(452) \\
3.66\end{array}$ \\
\hline MDF (Oe) & $\begin{array}{l}143 \pm 19(6) \\
142\end{array}$ & $\begin{array}{l}210 \pm 125(59) \\
164\end{array}$ & $\begin{array}{l}327 \pm 159(291) \\
288\end{array}$ & $\begin{array}{l}240 \pm 94(22) \\
216\end{array}$ & $\begin{array}{l}238 \pm 119(20) \\
206\end{array}$ & $\begin{array}{l}314 \pm 164(314) \\
267\end{array}$ & $\begin{array}{l}305 \pm 160(356) \\
259\end{array}$ \\
\hline$x\left(10^{-3} \mathrm{G} / \mathrm{Oe}\right)$ & $\begin{array}{l}1.59 \pm 0.29(7) \\
1.57\end{array}$ & $\begin{array}{l}2.55 \pm 1.37(84) \\
2.28\end{array}$ & $\begin{array}{l}1.25 \pm 0.92(361) \\
0.98\end{array}$ & $\begin{array}{l}1.98 \pm 0.45(31) \\
1.94\end{array}$ & $\begin{array}{l}2.41 \pm 1.20(32) \\
2.19\end{array}$ & $\begin{array}{l}1.38 \pm 1.12(389) \\
1.05\end{array}$ & $\begin{array}{l}1.49 \pm 1.13(452) \\
1.16\end{array}$ \\
\hline$Q_{n}$ & $\begin{array}{l}0.63 \pm 0.11(7) \\
0.62\end{array}$ & $\begin{array}{l}6.65 \pm 4.35(84) \\
5.29\end{array}$ & $\begin{array}{l}10.17 \pm 6.95(361) \\
8.01\end{array}$ & $\begin{array}{l}5.77 \pm 3.87(31) \\
4.12\end{array}$ & $\begin{array}{l}6.10 \pm 3.51(32) \\
4.61\end{array}$ & $\begin{array}{l}9.93 \pm 6.93(389) \\
7.77\end{array}$ & $\begin{array}{l}9.37 \pm 6.72(452) \\
7.17\end{array}$ \\
\hline$J_{S}(\mathrm{emu} / \mathrm{g})$ & $1.403(1)$ & $\begin{array}{l}2.352 \pm 0.905(26) \\
2.194\end{array}$ & $\begin{array}{l}1.178 \pm 0.673(72) \\
1.043\end{array}$ & $\begin{array}{l}1.860 \pm 0.142(9) \\
1.855\end{array}$ & $\begin{array}{l}2.441 \pm 0.872(13) \\
2.284\end{array}$ & $\begin{array}{l}1.284 \pm 0.389(77) \\
1.102\end{array}$ & $\begin{array}{l}1.488 \pm 0.898(99) \\
1.272\end{array}$ \\
\hline$J_{r}(\mathrm{emu} / \mathrm{g})$ & $0.266(1)$ & $\begin{array}{l}0.418 \pm 0.199(26) \\
0.365\end{array}$ & $\begin{array}{l}0.141 \pm 0.094(70) \\
0.099\end{array}$ & $\begin{array}{l}0.256 \pm 0.067(9) \\
0.249\end{array}$ & $\begin{array}{l}0.491 \pm 0.142(13) \\
0.469\end{array}$ & $\begin{array}{l}0.164 \pm 0.147(75) \\
0.108\end{array}$ & $\begin{array}{l}0.216 \pm 0.179(97) \\
0.142\end{array}$ \\
\hline$H_{c}(\mathrm{Oe})$ & $144(1)$ & $\begin{array}{l}200 \pm 70(26) \\
186\end{array}$ & $\begin{array}{l}153 \pm 85(70) \\
126\end{array}$ & $\begin{array}{l}206 \pm 61(9) \\
196\end{array}$ & $\begin{array}{l}205 \pm 77(13) \\
190\end{array}$ & $\begin{array}{l}154 \pm 83(75) \\
127\end{array}$ & $\begin{array}{l}166 \pm 83(97) \\
140\end{array}$ \\
\hline$J_{r} / J_{s}$ & $0.173(1)$ & $\begin{array}{l}0.180 \pm 0.056(26) \\
0.171\end{array}$ & $\begin{array}{l}0.122 \pm 0.049(70) \\
0.103\end{array}$ & $\begin{array}{l}0.143 \pm 0.030(9) \\
0.140\end{array}$ & $\begin{array}{l}0.210 \pm 0.055(13) \\
0.204\end{array}$ & $\begin{array}{l}0.125 \pm 0.050(75) \\
0.106\end{array}$ & $\begin{array}{l}0.138 \pm 0.057(97) \\
0.118\end{array}$ \\
\hline$J(5 \mathrm{kOe}) / J_{S}$ & $0.878(1)$ & $\begin{array}{l}0.856 \pm 0.051(26) \\
0.855\end{array}$ & $\begin{array}{l}0.721 \pm 0.123(70) \\
0.709\end{array}$ & $\begin{array}{l}0.849 \pm 0.006(9) \\
0.849\end{array}$ & $\begin{array}{l}0.869 \pm 0.036(13) \\
0.869\end{array}$ & $\begin{array}{l}0.729 \pm 0.125(75) \\
0.717\end{array}$ & $\begin{array}{l}0.759 \pm 0.124(97) \\
0.747\end{array}$ \\
\hline$T_{c}\left({ }^{\circ} \mathrm{C}\right)$ & $374(1)$ & $511 \pm 108(25)$ & $524 \pm 87(71)$ & $563 \pm 30(9)$ & $442 \pm 130(12)$ & $527 \pm 85(76)$ & $519 \pm 93(97)$ \\
\hline$J^{i} / J^{f}$ & $0.733(1)$ & $\begin{array}{l}0.932 \pm 0.173(25) \\
0.909\end{array}$ & $\begin{array}{l}0.872 \pm 0.145(71) \\
0.859\end{array}$ & $\begin{array}{l}0.951 \pm 0.035(9) \\
0.950\end{array}$ & $\begin{array}{l}0.891 \pm 0.254(12) \\
0.847\end{array}$ & $\begin{array}{l}0.878 \pm 0.142(76) \\
0.865\end{array}$ & $\begin{array}{l}0.886 \pm 0.154(97) \\
0.870\end{array}$ \\
\hline
\end{tabular}

Notes: Upper lines, arithmetic mean and standard deviation, with number of samples in parentheses. Lower lines, geometric mean. $J_{n}$, NRM intensity; MDF, median demagnetizing field; $x$, initial susceptibility; $Q_{n}$, Königsberger ratio; $J_{s}$, saturation magnetization; $J_{r}$, saturation remanence; $H_{c}$, coercive force; $T_{c}$, Curie temperature; $J^{i}, J f$, initial and final saturation magnetization at room temperature before and after heating to $700^{\circ} \mathrm{C}$ for thermomagnetic analysis. 


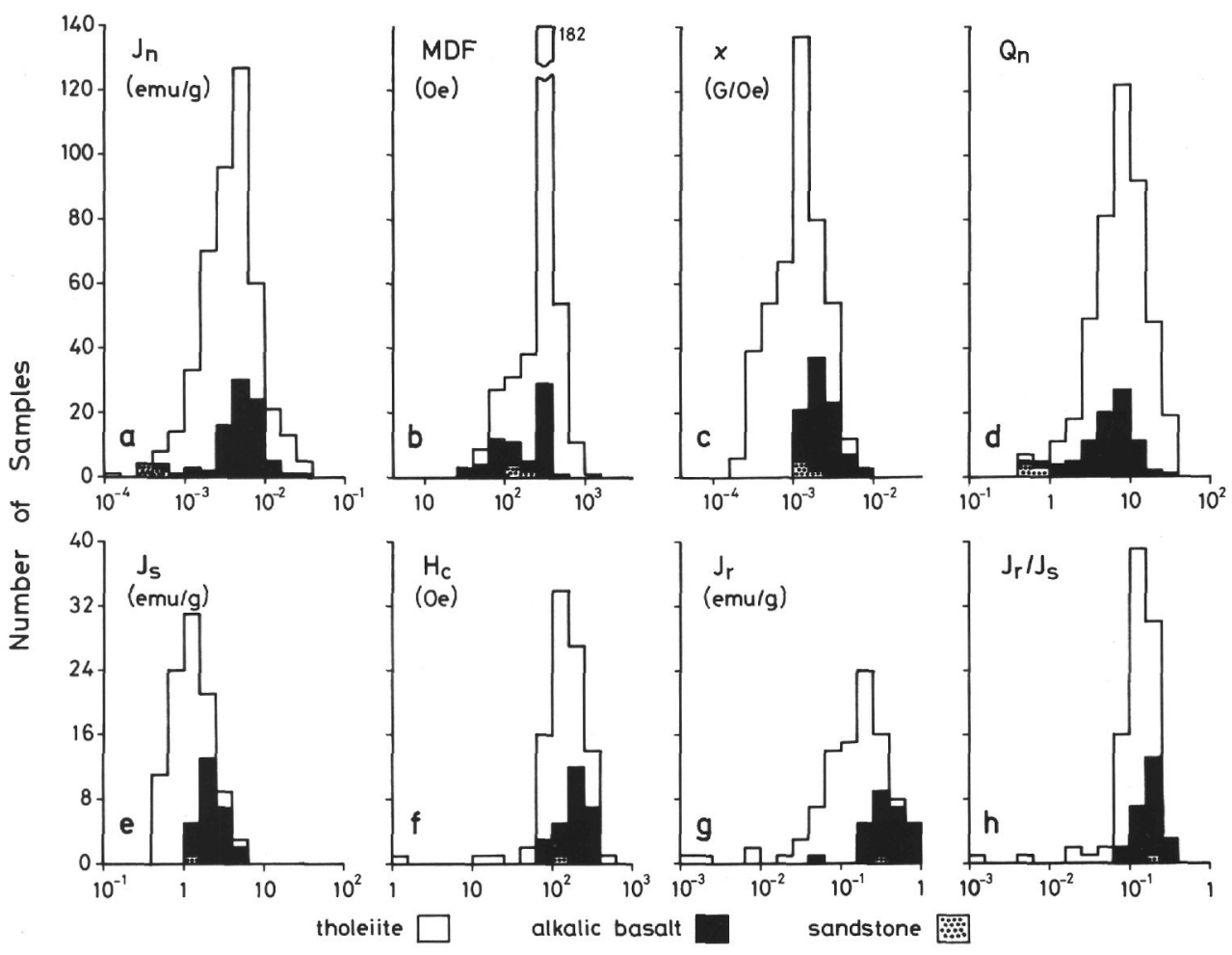

Figure 2. Distribution of magnetic properties data, Leg 55 basalt samples. $\mathrm{J}_{\mathrm{n}}=$ NRM intensity; $\mathrm{MDF}=$ median demagnetizing field; $\chi=$ initial susceptibility; $\mathrm{Q}_{\mathrm{n}}=$ Königsberger ratio; $\mathrm{J}_{\mathrm{s}}=$ saturation magnetization; $\mathrm{H}_{\mathrm{c}}=$ coercive force; $\mathrm{J}_{\mathrm{r}}$ = saturation remanence.

age, particularly in the surface layers of basaltic basement (e.g., Ozima et al., 1974). This possible effect was studied in DSDP basalts by Harrison (1976) in two different ways: change in site average NRM intensity with age and vertical variation of $J_{n}$ in individual deep holes. The results of his analyses were diverse, but it can be said that there is no definite trend of change in $J_{n}$ with either age or depth of the samples. In the Leg 55 basalts, there is no significant correlation of $J_{n}$ with depth subbottom; the correlation coefficients of regressions were 0.126 (Site 430), 0.080 (Site 432), and -0.081 (Site 433).

Kodama et al. (1978) calculated models of magnetization of Suiko seamount as a whole from surface geomagnetic anomalies. Although the fit of observed and calculated anomalies is poor, their preferred models suggest that the surface layers of Suiko have magnetization of $19 \times 10^{-3} \mathrm{emu} / \mathrm{cm}^{3}$ with an inclination of $-31^{\circ}$ $\pm 9^{\circ}$ and a declination of $213^{\circ} \pm 9^{\circ}$. Since these models assume that only the part of the seamount between depths of 1200 and 2000 meters are magnetized, intensity can be decreased to about $6 \times 10^{-3} \mathrm{emu} / \mathrm{cm}^{3}$ if the lower limit is placed between 3000 and 5000 meters. The models of Kodama et al. (1978) do not fit well with the observed magnetization at Site 433. Although the magnetization intensity may be adjusted by proper choice of the thickness of the source layer, or Site 433 data can be considered as representing only the local $J_{n}$ values, the magnetization direction cannot be reconciled. The mean inclination of $-45.7^{\circ} \pm 4.8^{\circ}$ at Site 433 is well defined with secular variation averaged out. We can conclude that much more bathymetric and magnetic data are necessary to define the magnetization of a seamount from just the surface data with an accuracy comparable to direct measurements.

\section{Median Demagnetizing Field (MDF)}

MDF represents the stability of remanences. In Leg 55 basalts, substantial secondary components were observed in the NRM of samples with an MDF of about 150 Oe or less (Kono, this volume). MDF in Leg 55 samples ranges between $30 \mathrm{Oe}$ and $1270 \mathrm{Oe}$, but its distribution is sharply peaked at about $300 \mathrm{Oe}$ (Figure $2 \mathrm{~b}$ ). Tholeiites have higher MDFs than alkalic basalts (Table 2). Differences in average MDF as well as $\chi$ and $J_{s}$ may be explained by the different grain size distributions of magnetic minerals in two types of basalts (discussed later). The range of MDFs is not much different from that of typical mid-oceanic ridge basalts, but the mean value is about twice as large (Lowrie, 1977). Notable in Leg 55 basalt is the near absence of samples with very low values of MDF ( $<60 \mathrm{Oe}$ ), which are often found in sea floor basalts.

\section{Initial susceptibility $\chi$ and Königsberger Ratio $Q_{n}$}

The initial susceptibility in Leg 55 basalts ranges from $0.19 \times 10^{-3}$ to $8.48 \times 10^{-3} \mathrm{G} / \mathrm{Oe}$. Tholeiite samples have smaller $\chi$ than alkalic basalts (Figure $2 c$, Table 1). The range of $\chi$ is similar to that of sea floor 


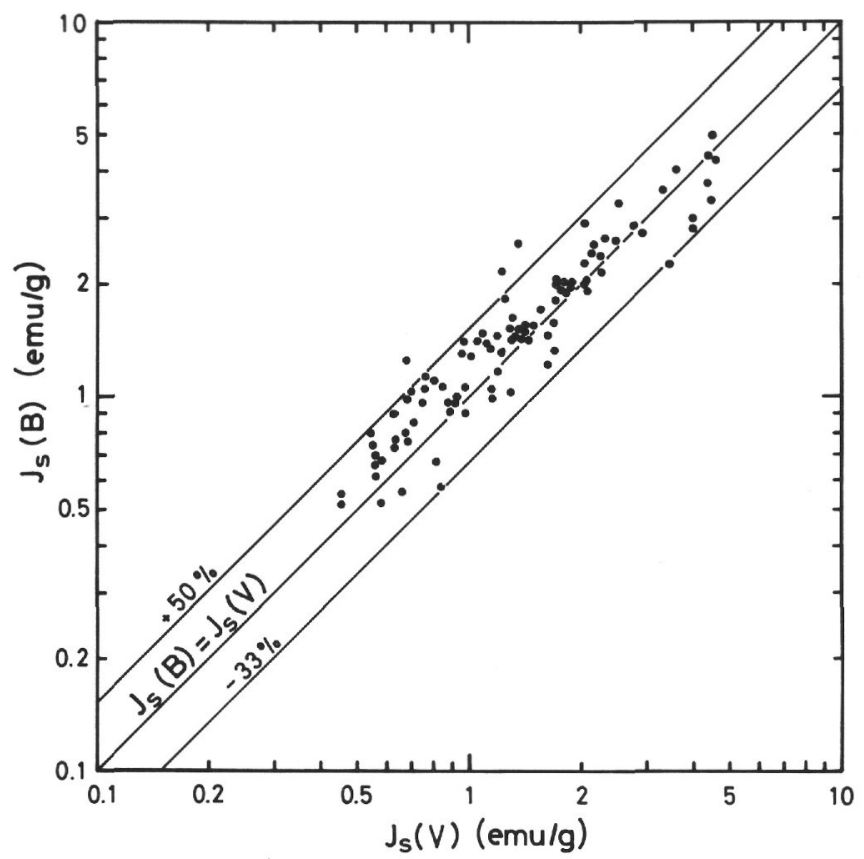

Figure 3. Comparison of saturation magnetizations measured by vibration sample magnetometer and by magnetic balance on different chips from the same minicore of Leg 55 basalts.

basalts; the present geometric mean value $\left(1.49 \times 10^{-3}\right.$ $\mathrm{G} / \mathrm{Oe}$ ) is much larger than that of the mean of 309 dredged samples, and is similar to the higher of the two modal values in 107 DSDP samples compiled by Lowrie (1974).

The Konigsberger ratio $Q_{n}=J_{n} / \chi H$ was calculated from $J_{n}, \chi$ of each sample, and the local field intensity $H$, for which I used the values 0.4079 (Ojin), 0.4260 (Nintoku), and 0.4459 Oe (Suiko), calculated from the International Geomagnetic Reference Field 1975.0 (Barraclough and Fabiano, 1977). $Q_{n}$ ranges from 0.44 to 37.78, with an arithmetic mean of 9.37 (Figure 2d, Table 1), indicating that in most Leg 55 samples the induced magnetization is not important in comparison with the NRM. The range and shape of the distribution of $Q_{n}$ of the present samples is more similar to that of dredged samples than to that of DSDP basalts (Lowrie, 1977).

\section{Saturation Magnetization $\boldsymbol{J}_{s}$}

Saturation magnetization values for different chips from the same sample are compared in Figure 3. In this figure, the abscissa is $J_{s}(\mathrm{~V})$, which was determined by extrapolating the $J-1 / H$ relation, measured by VSM, for the interval of $H=7$ to $12 \mathrm{kOe}$ to infinity. The ordinate $J_{s}(\mathrm{~B})$ is the magnetization, measured by a magnetic balance in a field of $5 \mathrm{kOe}$, multiplied by a factor $J_{S} / J(5 \mathrm{kOe})$, where $J(5 \mathrm{kOe})$ is the magnetization measured by VSM at $5-\mathrm{kOe}$ field and $J_{S} / J(5 \mathrm{kOe})$ is the reciprocal of the rate of saturation of this particular sample at $5 \mathrm{kOe}$. It is apparent that $J_{s}$ is reproducible to about a factor of 1.5 . Since there is no systematic difference between $J_{s}(\mathrm{~V})$ and $J_{s}(\mathrm{~B})$, the difference of two measurements indicates the degree of homogeneity of ferromagnetic minerals within minicore-sized samples. The arithmetic mean of $J_{s}(\mathrm{~V})$ and $J_{s}(\mathrm{~B})$ is taken as the characteristic value of a sample and listed as $J_{s}$ in Table 2 .

The range of $J_{s}$ in Leg 55 basalts $(0.423$ to 4.413 $\mathrm{emu} / \mathrm{g}$ ) is wider than ranges for DSDP samples from normal sea floors (e.g., Marshall, 1978; Hamano et al., 1979). The mean of $1.488 \mathrm{emu} / \mathrm{g}$ is larger than previously reported values. The distribution of $J_{s}$ of different rock types is quite similar to that of $\chi$; alkalic basalts have higher $J_{s}$ and $\chi$, and tholeiites have lower values (Figures 2, 1c, 2e). A strong correlation between these two parameters is expected, since to a first approximation both properties represent the amount of ferromagnetic minerals contained in a sample (Hamano et al., 1979). Such correlation among magnetic properties is discussed later.

\section{Saturation Remanent Magnetization $\boldsymbol{J}_{\boldsymbol{r}}$}

$J_{r}$ ranges from 0.01 to $0.790 \mathrm{emu} / \mathrm{g}$ in the Leg 55 basalts (Figure $2 \mathrm{~g}$ ). This range is also wider than the ranges of $J_{r}$ common in DSDP basalts. Hamano et al. (1979) report a range of 0.332 to $0.216 \mathrm{emu} / \mathrm{g}$ for 100 -m.y.-old sea floor in the Carribean Sea. A wider range of $J_{r}$ is quite reasonable if we consider the similar difference in $J_{s^{*}}$ In general, saturation remanence is a function of composition, content, and grain size of ferromagnetic minerals in rocks. The distribution of $J_{r}$ has a shape similar to the distributions of $\chi$ and $J_{s}$ (Figures $2 \mathrm{c}, 2 \mathrm{e}, 2 \mathrm{~g}$ ), even to the difference between tholeiites and alkalic basalts, which suggests that $J_{r}$ is controlled mostly by the magnetic mineral content, just as $J_{s}$ and $\chi$. Variation in composition is not great in these samples.

The ratio $J_{r} / J_{S}$ is controlled mainly by the grain size of ferromagnetic minerals, because composition and content affect $J_{r}$ and $J_{s}$ in a similar way. The range of $J_{r} / J_{s}$ ratio observed is 0.001 to 0.298 , with an arithmetic mean of 0.138 (Figure $2 \mathrm{~h}$ ). In its distribution, tholeiites and alkalic basalts do not differ much, except that some tholeiites have very low $J_{r} / J_{s}$ values corresponding to very small $J_{r}$. Dunlop (1973) showed that in magnetite grains with mean diameters $0.22 \mu \mathrm{m}$ to $0.037 \mu \mathrm{m}, J_{r} / J_{s}$ increases from 0.113 to 0.289 as the grain size decreases. A similar trend was observed by Parry (1965) for larger grains of magnetite. Most of the present samples have $J_{r} / J_{s}$ ratios comparable to those found in sea floor basalts (Hamano et all, 1979), and comparable also to sized magnetite samples in the pseudo-single domain range (Dunlop, 1973). Although the apparent grain size of titanomagnetites in Leg 55 basalts (10 to $\sim 20 \mu \mathrm{m}$ ) is much larger than the single domain-multidomain threshold as well as the apparent size in sea floor basalts $(\leq 5 \mu \mathrm{m})$, Leg 55 basalts show $J_{r} / J_{s}$ ratios typical of single domain to pseudo-single domain grains because of the subdivision of grains into smaller volumes by ilmenite lamellae (Strangway et al., 1968). The common ilmenite exsolution was observed by optical as well as 
scanning-electron microscopy (Kono, Clague, and Larson, this volume).

\section{Coercive Force $\boldsymbol{H}_{\boldsymbol{c}}$}

Coercive force of Leg 55 basalts is distributed between 1 and $399 \mathrm{Oe}$, with an arithmetic mean of $166 \mathrm{Oe}$ (Figure 2f). Parry (1965) showed that $H_{c}$ was about 100 Oe for magnetite specimens with grain diameter of 1.5 $\mu \mathrm{m}$, and that it decreased as the grain size became larger. Dunlop (1973) reports the same tendency for magnetite samples in single domain to pseudo-single domain size range; $H_{c}$ was 92 Oe for $0.22-\mu \mathrm{m}$ grains and 205 Oe for $0.037-\mu \mathrm{m}$ grains. Like $J_{r} / J_{s}$ ratios, most of the $H_{c}$ values for Leg 55 basalts fall in single domain to pseudo-single domain range if the magnetic minerals can be approximated by magnetite.

\section{Thermomagnetic Analyses}

Thermomagnetic analyses were carried out in vacuum, and three types of $J_{S}-T$ curves were observed. The first type (Figure 1a) is represented by only one sample, 432A 3-2, 67-69 $\mathrm{cm}$, which has a low Curie point of $187^{\circ} \mathrm{C}$. On cooling, the shape of the $J_{s}-T$ curve remains similar, but the $T_{c}$ is lowered to $108^{\circ} \mathrm{C}$, indicating a reduction of originally slightly oxidized titanomagnetite to stoichiometry. Although slight oxidation is supposed for the original sample, this sample can be interpreted as preserving the near-stoichiometric composition of the original titanomagnetite, without much effect of either high- or low-temperature oxidation.

The second type shows irreversible $J_{S}-T$ curves (Figures 1b, 1c). The thermomagnetic analyses were done in vacuum, so the irreversibility can be taken to indicate the presence of titanomaghemites, or cationdeficient titanomagnetites (Ozima and Ozima, 1971). Initial Curie points of these samples are between $242^{\circ} \mathrm{C}$ and $492^{\circ} \mathrm{C}$. As shown in Figure 1c, breakdown of the titanomaghemite phase starts below the Curie point in most of these samples; $T_{c}$ for these samples was determined by extrapolating the $J_{s}-T$ curve to the higher temperatures, and may therefore be in error by up to $50^{\circ} \mathrm{C}$. Six out of 23 alkalic-basalt samples and 14 out of 71 theoleiite samples belonged to this type.

The third and most important type has Curie points higher than $500^{\circ} \mathrm{C}$ and $J_{S}-T$ curves which are almost reversible. (Figure 1d). This type represents titanomagnetites oxidized at high temperature (Buddington and Lindsley, 1964; Ozima and Larson, 1970). Nearly 80 per cent of the samples belong to this type. The predominance of products of high-temperature oxidation in Leg 55 basalts is a major finding of these magnetic properties experiments. The interpretation of thermomagnetic curves is given later.

\section{Lattice Parameters of Magnetic Minerals}

Lattice constants of ferromagnetic minerals were measured for selected samples by the X-ray diffraction method. Samples with various initial Curie points were selected so that more type 2 than type 3 materials appear in this analysis. The results are shown in Table 3. Diffraction peaks between $20^{\circ}$ and $100^{\circ}$ were read from charts. About seven peaks corresponding to cubic phases were used in calculating lattice parameter $a$; the peak heights were taken as weights for individual data.

In addition to peaks of titanomagnetite (titanomaghemite) minerals, other diffraction peaks occurred for many samples. Among the most notable are ilmenite peaks at about $41.4^{\circ}(\mathrm{hkl}=104)$ and $62.8^{\circ}(204)$, and hematite peaks at about $42.2^{\circ}(104)$ and $69.9^{\circ}(116)$. (The X-ray wavelengths used in the analyses are 1.9359 $\AA\left[\mathrm{K} \alpha_{1}\right]$ and $1.9373 \AA[\mathrm{K} \alpha]$ from an iron target.) It is worth pointing out that cubic minerals in the samples showing hematite or ilmenite peaks have lattice parameters very near that of magnetite $(8.396 \AA)$. Results of $\mathrm{X}$-ray diffraction are in accord with other experiments relevant in identification of magnetic phases, i.e., thermomagnetic analysis and microscopic observation. These points are discussed in the next section.

\section{Ferromagnetic Minerals and Oxidation States}

In typical sea floor basalts, the ferromagnetic minerals are initially titanomagnetites $\left(\mathrm{Fe}_{3-x} \mathrm{Ti}_{x} \mathrm{O}_{4}\right)$ with a narrow range of composition near $x=0.6$. After formation, the titanomagnetite grains are generally subjected to low-temperature oxidation to titanomaghemites, with a corresponding increase in Curie temperature and decrease in lattice parameter (Ade-Hall et al., 1976; Johnson and Hall, 1978; Hamano et al., 1979). The extent of low-temperature oxidation is defined by a parameter $z$, where

$$
\mathrm{Fe}^{2+}+\frac{z}{2} \mathrm{O}-z \mathrm{Fe}^{3+}+(1-z) \mathrm{Fe}^{2+}+\frac{z}{2} \mathrm{O}^{2-}
$$

and $\mathrm{z}=0$ and $\mathrm{z}=1$ describe completely unoxidized and completely oxidized conditions, respectively (Readman and O'Reilly, 1971).

In the present samples, low-temperature oxidation is not the predominant process. Instead, about 80 per cent of the samples show nearly reversible $J_{s}-T$ curves, with Curie temperatures higher than $500^{\circ} \mathrm{C}$, indicating that they are products of high-temperature oxidation. In this oxidation, originally Ti-rich titanomagnetite decomposes into Ti-poor magnetite solid solution and Ti-rich hemoilmenite. If the oxidation proceeds further, magnetite becomes hematite, and the hemoilmenite phase decomposes into pseudobrookite and hematite (Buddington and Lindsley, 1964; Ozima and Larson, 1970). At the moderate oxidation stage, the ilmenite phase exsolves in the (111) planes of titanomagnetite and effectively makes the magnetic grain size much smaller than the one optically observed (Strangway et al., 1968). Ilmenite intergrowths were commonly observed by reflection microscopy of polished sections (Kono, Clague, and Larson, this volume). The existence of hematite and ilmenite peaks in X-ray diffraction charts also supports the high-temperature oxidation scheme. The presence of optically unresolvable micro-intergrowths are also demonstrated by using a scanning electron microscope (Kono, Clague, and Larson, this volume). 
TABLE 3

Results of X-ray Diffraction Analysis and Correlation with Other Data

\begin{tabular}{|c|c|c|c|c|c|c|c|c|}
\hline \multirow{2}{*}{$\begin{array}{c}\text { Sample } \\
\text { (Interval in } \mathrm{cm} \text { ) }\end{array}$} & \multirow{2}{*}{$\begin{array}{l}\text { Rock } \\
\text { Type }\end{array}$} & \multirow{2}{*}{$\begin{array}{c}T_{c} \\
\left({ }^{\circ} \mathrm{C}\right)\end{array}$} & \multicolumn{3}{|c|}{ Lattice Constant } & \multicolumn{2}{|c|}{ Oxidation } & \multirow[b]{2}{*}{ Remarks } \\
\hline & & & $\overline{\mathrm{N}}$ & a & $\overline{\text { s.d. }}$ & Type & $\overline{\text { Stage }}$ & \\
\hline $432 \mathrm{~A}-3-2,67-69$ & $\mathrm{~A}$ & $187 \pm 7$ & 7 & 8.4659 & .0047 & NO & $\mathrm{N}$ & \\
\hline $432 \mathrm{~A}-5-2,69-71$ & A & $299 \pm 20$ & 7 & 8.4279 & .0020 & LT & L-M & \\
\hline $433 \mathrm{C}-16-1,80-82$ & $\mathrm{~T}$ & $340 \pm 30$ & 7 & 8.3950 & .0118 & LT & $\mathrm{L}$ & \\
\hline $433 C-21-4,101-103$ & $\mathrm{~T}$ & $375 \pm 35$ & 7 & 8.4154 & .0036 & LT & L-M & \\
\hline $432 \mathrm{~A}-4-1,120-122$ & $\mathrm{~A}$ & $391 \pm 40$ & 7 & 8.4015 & .0047 & LT & L-M & \\
\hline $433 C-21-4,64-66$ & $\mathrm{~T}$ & $421 \pm 45$ & 8 & 8.3936 & .0097 & LT & L-M & Ilmenite peaks present \\
\hline $433 \mathrm{C}-29-2,115-117$ & $\mathrm{~T}$ & $492 \pm 50$ & 7 & 8.3758 & .0055 & LT? & M-H & \\
\hline $430 A-5-2,30-32$ & A & $520 \pm 5$ & 7 & 8.4225 & .0047 & HT & $\mathrm{M}-\mathrm{H}$ & \\
\hline $433 C-22-1,104-106$ & $\mathrm{~T}$ & $537 \pm 5$ & 7 & 8.3840 & .0064 & HT & M-H & Ilmenite peaks present \\
\hline $433 C-10-4,69-71$ & $\mathrm{~T}$ & $572 \pm 3$ & 6 & 8.3728 & .0059 & HT & $\mathrm{H}$ & Hematite peak present \\
\hline $433 \mathrm{C}-36-3,60-62$ & $\mathrm{~T}$ & $577 \pm 3$ & 7 & 8.3855 & .0061 & HT & $\mathrm{M}-\mathrm{H}$ & Ilmenite and hematite peaks present \\
\hline
\end{tabular}

Notes: Rock Type: alkalic basalt (A) or tholeiite (T). $T_{c}$ : Curie temperature and estimated maximum ambiguity. Lattice constant: $\quad \mathrm{N}=$ number of peaks, $\mathrm{a}=$ lattice constant, and s.d. = standard deviation for cubic phase. Oxidation Type: type of $J_{S}-T$ curve, indicating the principal type of oxidation: not oxidized (NO), low-temperature (LT), or hightemperature (HT) oxidation. Oxidation Stage: stages of high-temperature oxidation, defined by reflection microscopy: no $(\mathrm{N})$, low $(\mathrm{L})$, moderate $(\mathrm{M})$, or high $(\mathrm{H})$.

Figure 4 shows histograms of Curie temperature and high-temperature oxidation stage and their mutual correlation among the present samples. Existence of the titanomaghemite phase was inferred by two independent methods. The method of optical observation and its results are explained by Kono, Clague, and Larson in this volume. The other method is the one proposed by Ozima and Ozima (1971), namely to identify titanomaghemite by the irreversible humps in thermomagnetic curves obtained in vacuum (Figures $1 \mathrm{~b}, 1 \mathrm{c}$ ). The two methods were applied independently; i.e., without knowing the results of the other. As seen from Figure 4, in most cases both methods give consistent results. This suggests the reliability of the two methods. Several features should be pointed out from Figure 4. First, most of the samples have very high Curie points, and only one sample has the low Curie point corresponding to unoxidized titanomagnetite. Second, optically highly oxidized samples ( $\mathrm{H}$ and $\mathrm{M}-\mathrm{H}$ ) have high Curie temperatures, but the reverse is not true. Third, the samples with Curie points between $200^{\circ} \mathrm{C}$ and $500^{\circ}$ invariably show some degree of irreversibility of $J_{s}-T$ curves. And last, titanomaghemites appear in samples where original high-temperature oxidation was not severe; i.e., in L or L-M samples. Clearly, these observations show the oxidation state of the present samples.

Optically, oxidation stages $\mathrm{M}$ and $\mathrm{H}$ of titanomagnetites are characterized by ilmenite lamellae and pseudobrookite (with hematite), respectively (Kono, Clague, and Larson, this volume). The reactions can be expressed as

$$
\begin{gathered}
\mathrm{Fe}_{3-x} \mathrm{Ti}_{x} \mathrm{O}_{4}+\frac{x}{6} \mathrm{O}_{2} \rightarrow x \mathrm{TiFeO}_{3}+\left(1-\frac{2}{3} x\right) \mathrm{Fe}_{3} \mathrm{O}_{4}(1) \\
\mathrm{Fe}_{3} \mathrm{O}_{4}+\frac{1}{4} \mathrm{O}_{2} \rightarrow \frac{3}{2} \mathrm{Fe}_{2} \mathrm{O}_{3}
\end{gathered}
$$$$
\mathrm{TiFeO}_{3}+\frac{1}{4} \mathrm{O}_{2}-\frac{1}{2} \mathrm{TiO}_{2}+\frac{1}{2} \mathrm{TiFe}_{2} \mathrm{O}_{5}
$$

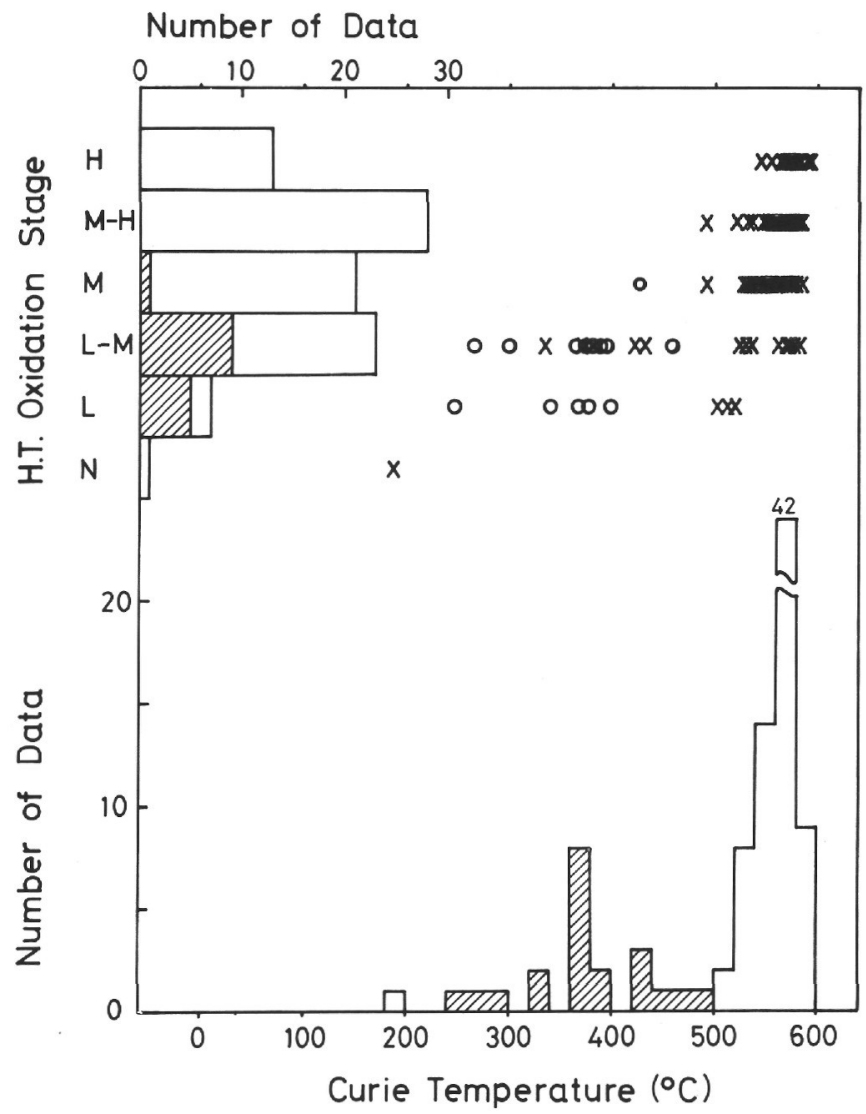

Figure 4. Histograms of Curie points (bottom) and hightemperature axidation stages (upper left), and the correlation between these two properties (upper right). Samples containing low-temperature-oxidized phase are indicated by hachures and circles. Titanomaghemitization is inferred from $\mathrm{J}_{\mathrm{s}}-\mathrm{T}$ curves (histogram of $\mathrm{T}_{\mathrm{c}}$ ) or observed by reflection microscopy (histogram of oxidation and correlation diagram). 
In thermomagnetic analysis, the measured Curie point represents some average over coexisting ferromagnetic phases. Curie temperature increases as reaction (1) proceeds and reaches the Curie tempeature of magnetite $\left(585^{\circ} \mathrm{C}\right)$, when ilmenite and magnetite completely separate. Oxidation continues further, but the observed Curie point does not change afterward, since the products of oxidation reactions (2) are either non-magnetic or have much weaker magnetization than the (remaining) magnetite. This explains the second point. The present samples can be regarded as a random sampling of the recovered cores, but the high percentage of Curie points higher than $500^{\circ} \mathrm{C}$ may be caused in part by deposition or the drilling process. High-temperature oxidation does not proceed much in the top part of a lava flow, where cooling is rapid and not enough time is available at high temperatures (e.g., Ade-Hall et al., 1968). But this part of the flow is also fragile because of pores and cracks, is susceptible to later erosion, and also may be easily lost while drilling.

Observations about the titanomaghemite phase pose some interesting problems. It is unlikely that original titanomagnetites had only Curie points lower than $200^{\circ} \mathrm{C}$ (near stoichiometry) or higher than $500^{\circ} \mathrm{C}$ (hightemperature oxidation products); Curie points in between represent effects of both high- and low-temperature oxidation. It is admittedly difficult to recognize irreversible humps in $J_{s}-T$ curves when original Curie points exceed $500^{\circ} \mathrm{C}$ (see Figure 1c). But microscopic observations confirm that titanomaghemite is absent in such samples, whereas in most low-Curie-point samples titanomaghemites were identified by color changes and irregular shrinkage cracks (Kono, Clague, and Larson, this volume). That titanomaghemites appear only in low-oxidation-stage samples is naturally understood if we notice the complementariness of high- and lowtemperature oxidation. The abundance of titanomaghemitization in samples having low Curie temperature may indicate that they have been in a favorable environment, i.e., in sea water, for a prolonged time.

Figure 5 is a plot of $T_{c}$ versus $a$ of ferromagnetic minerals in Table 3. It is clear that samples of NO and HT types have lattice constants and Curie temperatures close to those of titanomagnetite $(x=0.6 \sim 0.7)$ and magnetite $(x=0)$, respectively. Products of low-temperature oxidation have much larger errors in $T_{c}$, so it is difficult to decide the exact trend. The data may be explained by either homogeneous oxidation (parallel to the trend shown for $x=0.7$ and $x=0.6$; T. Nishitani, in preparation, (1979) or low-temperature oxidation plus some compositional change. We need more data to clarify this process.

\section{DISCUSSION}

Table 4 summarizes correlations among various magnetic properties. Only relations with correlation coefficients greater than 0.4 are listed. A strong correlation is expected between MDF and $H_{c}$, but it does not appear in the table, because the two properties were measured only on different samples.

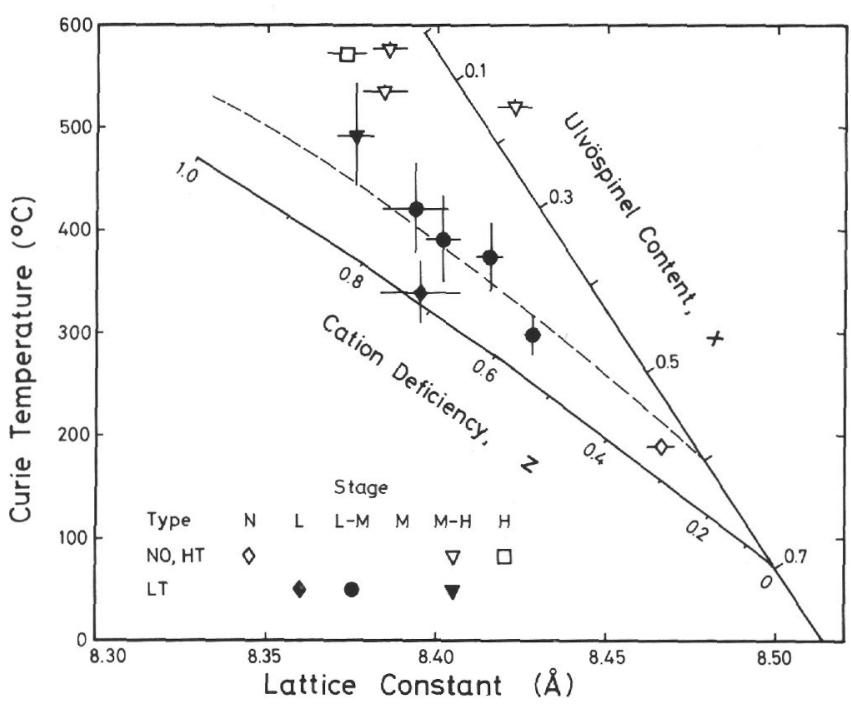

Figure 5. Relation between Curie point and lattice constant of ferromagnetic minerals. High- and lowtemperature oxidation states are expressed by different symbols. Also shown are $\mathrm{T}_{\mathrm{c}}-\mathrm{a}$ relations for stoichiometric titanomagnetite and titanomaghemite with $\mathrm{x}=0.7$ and $0.6(T$. Nishitani, in preparation, 1979).

Some of the magnetic properties also show significant correlation with sub-bottom depth, but correlations for Holes $430 \mathrm{~A}$ and $432 \mathrm{~A}$ are perhaps spurious because the number of samples is not sufficient to define statistical correlation ( $\mathrm{N}=9$ and 13). At Site 433 (Suiko), MDF, $\chi$ and $J_{s}$ have relatively high correlation coefficients with depth of $0.296,-0.393$ and -0.362 , respectively. As will be discussed later, these trends can be explained in terms of the change in magnetic grain size; the mean magnetic grain size decreases with depth in this hole, causing a decrease in stability (MDF) and an increase in the total amount of magnetic phase ( $J_{S}$ and $\chi)$. This, in part, represents the effect of change in chemical composition of basalt. Alkalic basalts (upper layers in Hole $433 C$ ), on the whole, have larger $J_{s}$ and $\chi$ and smaller MDF, in comparison with tholeiites (lower layers in Hole 433C). Such changes with depth do not seem to be universal; MDF and $J_{s}$ increase and $\chi$ stays constant with depth in Hole 430A, whereas MDF

TABLE 4

Some Regressions $(y=a+b x)$ between Magnetic Properties

\begin{tabular}{|c|c|c|c|c|c|c|c|}
\hline & $x$ & & $y$ & $\mathrm{~N}$ & $\mathrm{a}$ & b & $\mathrm{r}$ \\
\hline MDF & (Oe) & $x$ & $\left(10^{-3} \mathrm{G} / \mathrm{Oe}\right)$ & 356 & 2.421 & -0.003 & -0.466 \\
\hline MDF & (Oe) & $Q_{n}$ & & 356 & 4.459 & 0.019 & 0.420 \\
\hline$x$ & $\left(10^{-3} \mathrm{G} / \mathrm{Oe}\right)$ & $J(5 \mathrm{kOe}) / J_{S}$ & & 94 & 0.632 & 0.076 & 0.754 \\
\hline$\hat{Q}_{n}$ & & $J_{n}$ & $\left(10^{-3} \mathrm{emu} / \mathrm{cm}^{3}\right)$ & 452 & 1.533 & 0.371 & 0.553 \\
\hline$J_{s}(\mathrm{~V})$ & $(\mathrm{emu} / \mathrm{g})$ & $J_{r}$ & $(\mathrm{emu} / \mathrm{g})$ & 97 & -0.025 & 0.169 & 0.883 \\
\hline$J_{s}(\mathrm{~V})$ & (emu/g) & $J(5 \mathrm{kOe}) / J_{S}$ & & 97 & 0.616 & 0.100 & 0.753 \\
\hline$J_{s}$ & $(\mathrm{emu} / \mathrm{g})$ & $x$ & $\left(10^{-3} \mathrm{G} / \mathrm{Oe}\right)$ & 96 & -0.123 & 1.205 & 0.875 \\
\hline$J_{r}^{s}$ & (emu/g) & $\hat{J}_{n}$ & $\left(10^{-3} \mathrm{emu} / \mathrm{cm}^{3}\right)$ & 94 & 2.226 & 7.906 & 0.454 \\
\hline$J_{r}$ & (emu/g) & $\mathrm{x}$ & $\left(10^{-3} \mathrm{G} / \mathrm{Oe}\right)$ & 94 & 0.688 & 4.705 & 0.675 \\
\hline$J_{r}$ & (emu/g) & $\hat{J}_{r} / J_{S}$ & & 97 & 0.092 & 0.216 & 0.680 \\
\hline & (emu/g) & $J(5 \mathrm{kOe}) / J_{S}$ & & 97 & 0.648 & 0.513 & 0.740 \\
\hline$J_{r} / J_{S}$ & & $J_{n}$ & $\left(10^{-3} \mathrm{emu} / \mathrm{cm}^{3}\right)$ & 94 & 0.299 & 26.25 & 0.485 \\
\hline$J_{r} / J_{S}$ & & $J(5 \mathrm{kOe}) / J_{S}$ & & 97 & 0.575 & 1.328 & 0.608 \\
\hline$J(5 \mathrm{kOe}) / J_{S}$ & & $J^{i} / J f$ & & 95 & 0.506 & 0.499 & 0.402 \\
\hline
\end{tabular}

Notes: $\mathrm{N}=$ number of data; $\mathrm{r}=$ correlation coeff icient. 
decreases and $\chi$ and $J_{s}$ increase with depth in Hole 432A, with comparable correlation coefficients. We can conclude that apparent correlation of magnetic properties with depth is caused by such changes in the characteristics of rocks as chemical composition, cooling rate, porosity, etc., and does not represent the direct effect of sub-bottom depth on magnetic properties. Occurrence of titanomagnemitization does not correlate with depth.

\section{Parameters Relevant to Stability of NRM}

Figure 6 shows correlation of $\chi$ and $Q_{n}$ with MDF. Generally, alkalic basalts have large $\chi$ and low MDF, whereas tholeiites have small $\chi$ and high MDF. Volcaniclastic sandstone samples from Holes 430A and 432A have values similar to those for alkalic basalts. The low $Q_{n}$ values of sandstones are, of course, the result of low NRM. In Figure 6a, the data seem to distribute below an envelope in the form of $\chi \cdot \mathrm{MDF}=$ constant, which perhaps represents the balance between ferromagnetic minerals of larger (contributing to $\chi$ ) and smaller grain sizes (contributing to MDF) in otherwise similar rocks. The correlations in Figure 6 show that the MDF is a good parameter characterizing the stability of NRM, the larger the MDF, the larger $Q_{n}$ and the smaller $\chi$.

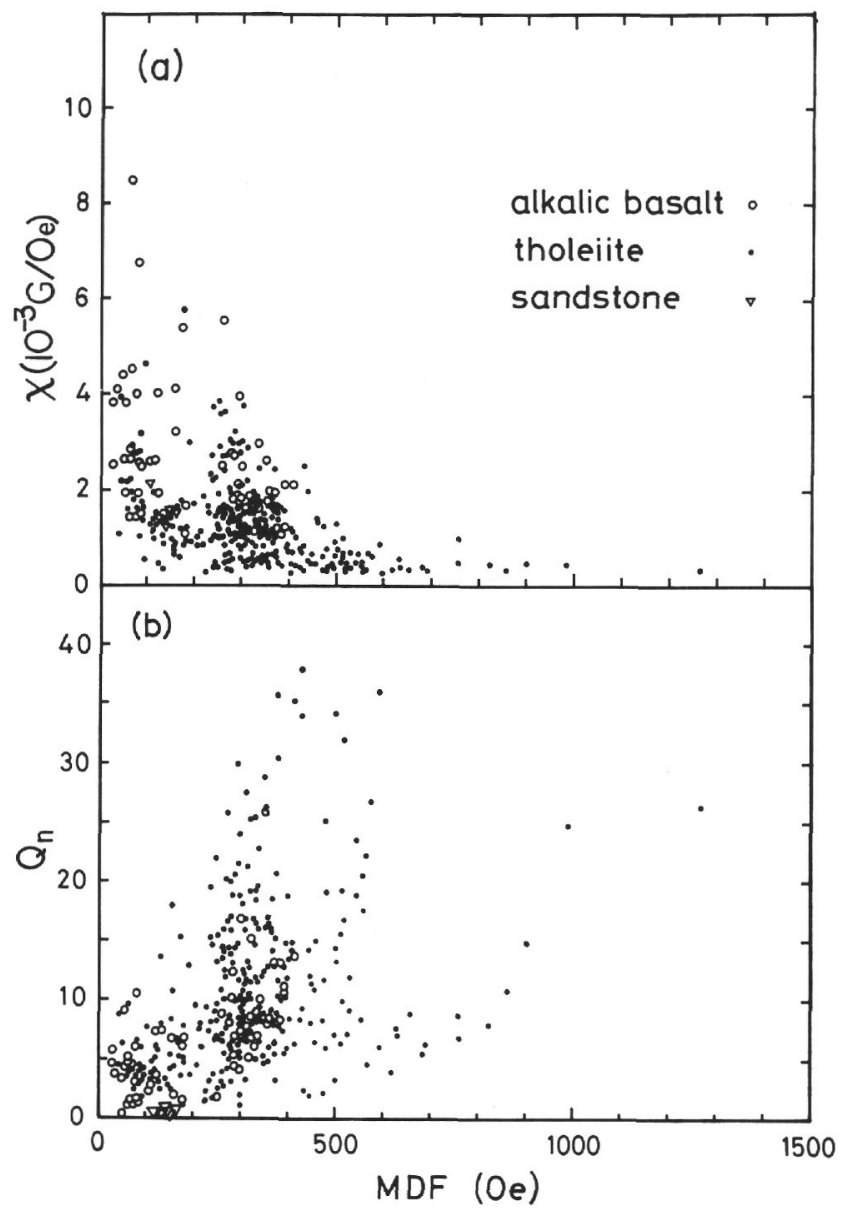

Figure 6. Relations between (a) MDF and $\chi$ and (b) MDF and Königsberger ratio.

\section{Cooling History and Grain Size of Ferromagnetic Minerals}

Magnetic properties of basalts reflect many influences that prevailed at the time of eruption and changes that have occurred since. Since the secondary, low-temperature oxidation is not dominant in the Leg 55 basalts, the magnetic properties of these basalts are mostly determined by conditions at the time of initial cooling. Effects of cooling on the concentration and grain diameter are considered as follows (Marshall and Cox, 1971): (1) The magnetic-mineral concentration increases with slower cooling, because of crystal growth, until the rock is completely crystalline, after which it will be constant. (2) The grain size becomes larger with slower cooling, until the grains suffer high-temperature oxidation, which reduces the effective grain size.

The saturation magnetization $J_{s}$ is an intrinsic parameter and a non-decreasing function of magnetic mineral concentration, so it can be taken to represent the effect of the concentration. On the other hand, the susceptibility $\chi$ is a function of concentration, but is also structure-sensitive. Figure 7 shows the relation between $J_{s}$ and $\chi$. Apparently, there is a linear relation between these two parameters, indicating that the structure control affects $\chi$ in these rocks in similar ways. On closer examination, it seems that the linear relation between $J_{s}$ and $\chi$ differs for alkalic basalts and tholeiites. This may indicate structural differences between different types of basalts, but the meaning is not clear. The oxidation type (HT or LT) does not affect the $J_{s}-\chi$ relation, but the only NO sample (not oxidized) is far apart from the general trend. Hamano et al. (1979) showed a similar linear $J_{s^{-}} \chi$ linear relation among typical sea floor basalts, but the gradient is different. The data for the single NO sample lie very close to but slightly below

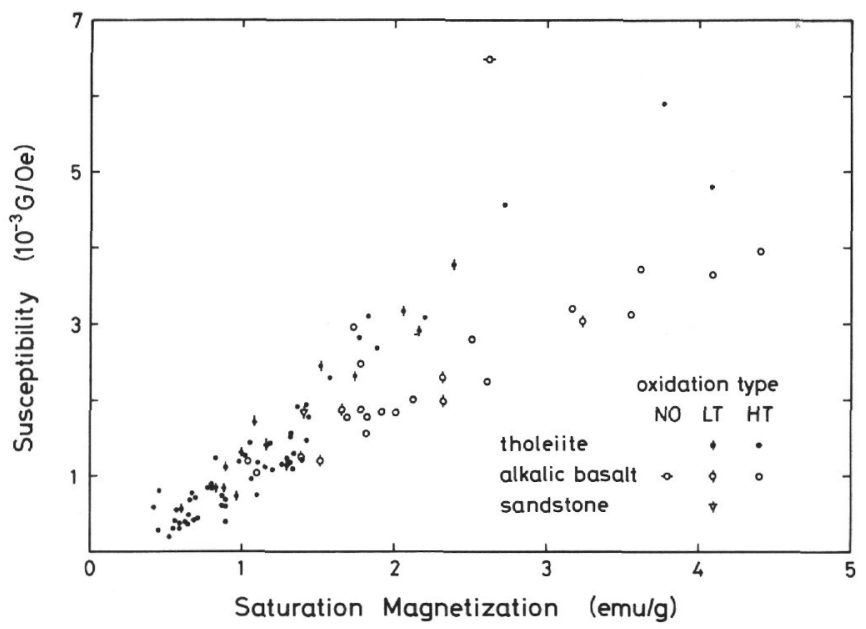

Figure 7. Relation between saturation magnetization $\mathrm{J}_{\mathrm{s}}$ and susceptibility $\chi$. Oxidation type (NO, LT, or HT) and rock type are indicated by different symbols. It can be seen that tholeiites and alkalic basalts (including a sandstone sample) follow slightly different trends. 
the $J_{s^{-}} \chi$ linear relation of Hamano et al. The $J_{s^{-}} \chi$ relations of sea floor basalts and of the present samples can be interpreted to correspond to titanomagnetites in some of which grain subdivision by ilmenite lamellae, caused by high-temperature oxidation, has occurred and in some of which it has not.

Figure 8 summarizes the relation of $J_{s}$ to $J_{r}$, to $J_{r} / J_{s}$, and to $J(5 \mathrm{kOe}) / J_{s}$. Saturation remanence $J_{r}$ varies linearly with $J_{s}$, but the relation is not very clear. It should be pointed out that, just like the $J_{s}-\chi$ relation, the $J_{s}-J_{r}$ line cuts the abscissa at about $J_{s}=0.4 \mathrm{emu} / \mathrm{g}$. The change of $J_{r} / J_{s}$ is more broad, but it appears that $J_{r} / J_{s}$ has a maximum of about 0.3 at $J_{s}=1.5 \sim 2$ $\mathrm{emu} / \mathrm{g}$. The rate of saturation at $5 \mathrm{kOe}, J(5 \mathrm{kOe}) / J_{s}$, shows a clear dependence on $J_{s}$. These observations can be interpreted systematically in terms of crystal growth in the cooling process, or grain size, of titanomagnetite minerals.

In quenched parts of rocks such as glass, ferromagnetic minerals are either not crystallized yet or so small that they are in superparamagnetic (SPM) state. With slower cooling, the minerals become large enough to be single domain (SD), and gradually grow to pseudo-single domain (PSD) and multidomain (MD) sizes. Hamano et al. (1979) observed such a change in a

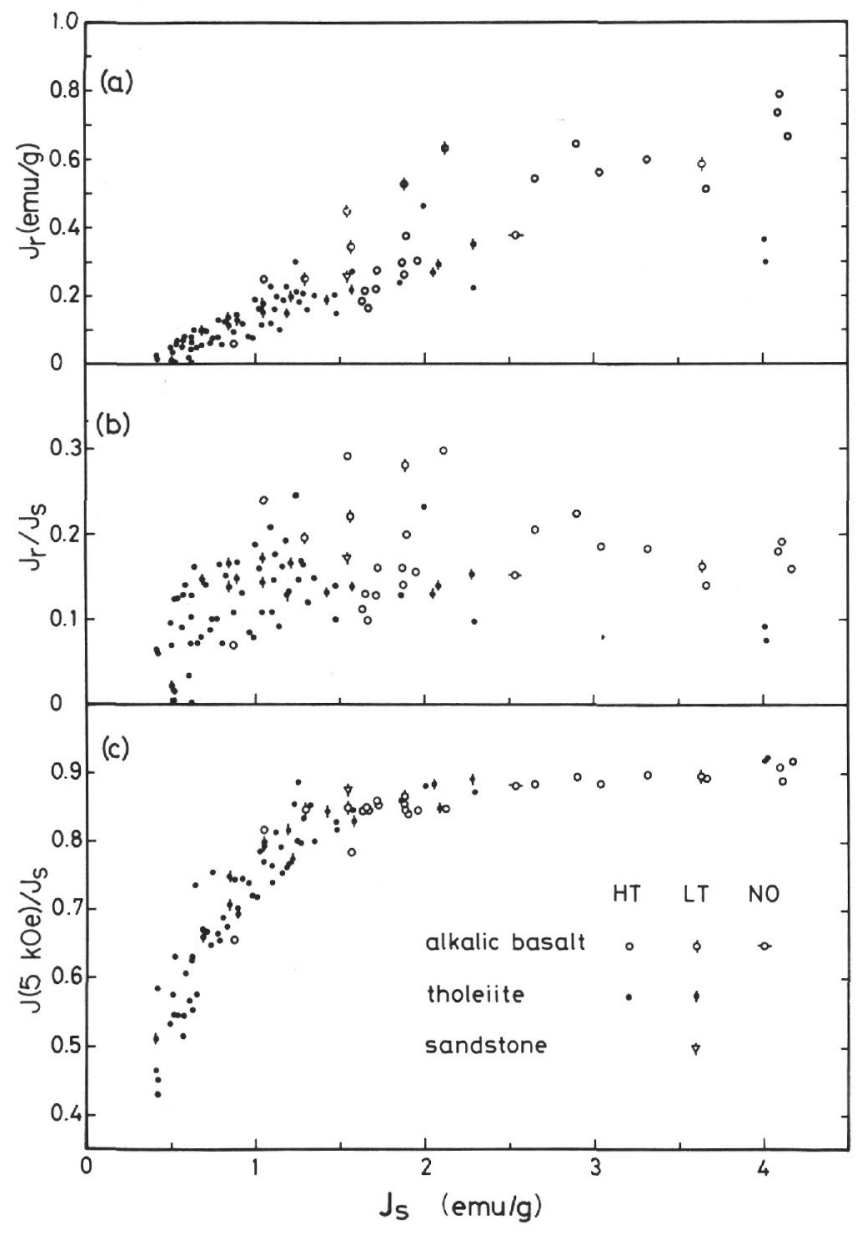

Figure 8. Relations between $\mathrm{J}_{\mathrm{s}}$ and (a) $\mathrm{J}_{\mathrm{r}}\left(\right.$ b) $\mathrm{J}_{\mathrm{r}} / \mathrm{J}_{\mathrm{s}}$, (c) $\mathrm{J}(5 \mathrm{kOe}) / \mathrm{J}_{\mathrm{s}}$ in Leg 55 basalts. piece of pillow surface only $5 \mathrm{~cm}$ thick in Hole $418 \mathrm{~A}$ basalt. $J_{r} / J_{s}$ ratio increased from 0.003 to 0.333 , corresponding to a change in $J_{s}$ from 0.066 to $0.312 \mathrm{emu} / \mathrm{g}$, from the surface to $3 \mathrm{~cm}$ inside a pillow margin sample. Farther inside, $J_{s}$ continued to increase, but $J_{r} / J_{s}$ decreased. In other basalts from Holes 417D and 418A, $J_{r} / J_{s}$ decreased from about 0.3 to 0.05 , corresponding to $J_{s}$ of 0.3 to $1.5 \mathrm{emu} / \mathrm{g}$. The overall change in pillow margin and basalt samples is compatible with the scheme explained above.

In the present samples, the maximum in $J_{r} / J_{S}$ is very broad, but seems to be between $J_{s}$ of 1.5 and $2 \mathrm{emu} / \mathrm{g}$. The difference in the position of the maximum may represent the effect of bulk chemistry, but otherwise the same scheme seems to fit the present data. For $J_{s}$ values less than $0.4 \mathrm{emu} / \mathrm{g}$, crystals had not grown yet, or the SPM component is dominant and $J_{r}$ (and also $\chi$ ) is negligible. Between $0.4 \mathrm{emu} / \mathrm{g}$ and $1.5 \mathrm{emu} / \mathrm{g}$, SD grains increase at the expense of SPM grains, as reflected in the increase of both $J_{r} / J_{s}$ and $J(5 \mathrm{kOe}) / J_{s}$. After $1.5 \mathrm{emu} / \mathrm{g}, J(5 \mathrm{kOe}) / J_{s}$ continues to change, but the change is small because most of the grains have already passed the SPM range. If the high-temperature oxidation is absent, $J_{r}$ may also decrease after 1.5 emu/g, just as does $J_{r} / J_{s}$, because grains become too big to be in SD state. In the Leg 55 samples, however, hightemperature oxidation proceeds at slower cooling rates, and the effective grain size of ferromagnetic grains is smaller than the actual grain size. This is perhaps why the maximum of $J_{r} / J_{s}$ is very broad and displaced to a large value of $J_{s}$, and why $J_{r}$ continues to increase with $J_{s}$ at a reduced rate beyond the maximum in $J_{r} / J_{s}$. Whether or not the grains underwent secondary oxidation (titanomaghemitization) does not seem to affect the general trend. The scatter of data in $J_{r}-J_{s}$ and $J_{r} / J_{s}-J_{s}$ diagrams (Figures $8 \mathrm{a}, 8 \mathrm{~b}$ ) may perhaps be caused by the difference in the grade of the original high-temperature oxidation.

\section{Intensity of NRM}

Table 4 shows that the intensity of the remanence, $J_{n}$, does not depend strongly on any other magnetic properties. $J_{n}$ values of the present samples have highest correlation with $J_{r} / J_{s}$ and $J_{r}$. Figure 9 a shows the relation between $J_{n}$ and $J_{r} / J_{s}$. A positive linear relation exists but it is a poor one. In Figure 9b, the NRM intensity $J_{n}$ is normalized by saturation magnetization $J_{s}$. In this diagram, tholeiites show slight correlation between $J_{n} / J_{s}$ and $J_{r} / J_{s}$, and have larger $J_{n} / J_{s}$ ratios than alkalic basalts, which do not show any correlation. As in the relation between $J_{s}$ and $\chi$, the difference in behavior between tholeiites and alkalic basalts suggests some magnetic difference, but the reason of such difference is not clear.

\section{Change in Saturation Magnetization Induced By Heating}

In thermomagnetic analyses, most samples show irreversible changes to some degree. The most notable ones occur in titanomaghemite-bearing rocks (Figures $1 \mathrm{~b}, 1 \mathrm{c})$, and can be interpreted as the consequence of 


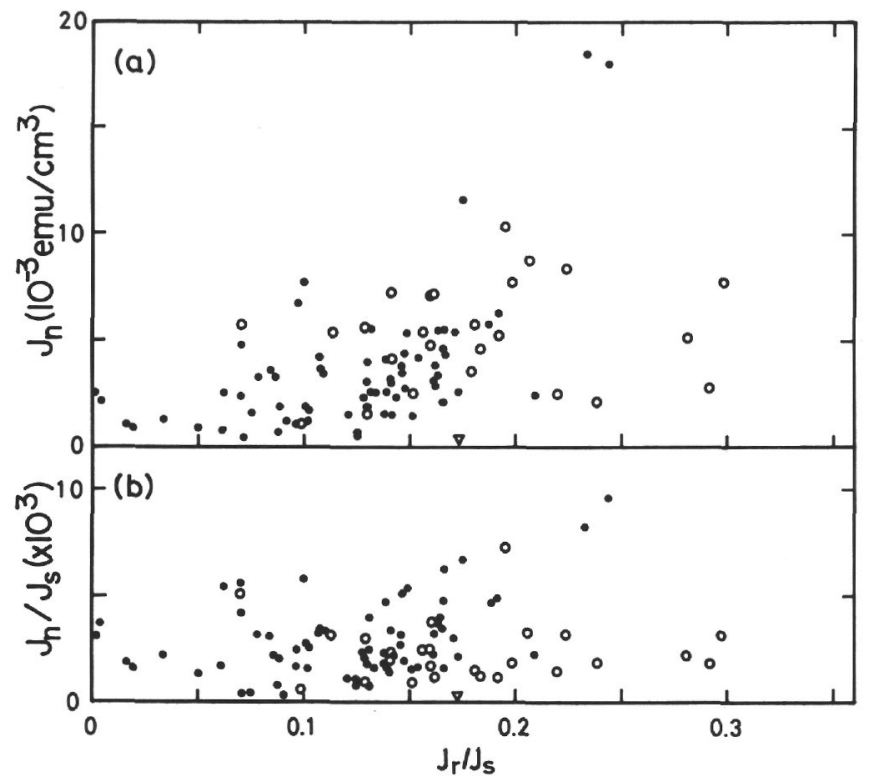

Figure 9. (a) NRM intensity $\mathrm{J}_{\mathrm{n}}$ and (b) $\mathrm{J}_{\mathrm{n}} / \mathrm{J}_{\mathrm{s}}$ as functions of $\mathrm{J}_{\mathrm{r}} / \mathrm{J}_{\mathrm{s}}$. See Figure 7 for explanation of symbols.

unmixing of metastable titanomaghemite phase into Tipoor magnetite solid solution (cubic phase) and Ti-rich ilmenite solid solution (rhombohedral phase). In this case, $J_{s}$ usually increases irreversibly after heating (Figure 1b), because the low-temperature-oxidized phase has lower saturation magnetization than the corresponding titanomagnetite phase (Readman and O'Reilly, 1972). Irreversible change in $J_{s}$ is also observed, however, in rocks which do not show any trace of low-temperature oxidation. In this case, the change in Curie temperature is very small, so that a big change in the chemistry of ferromagnetic minerals is not expected. Thermomagnetic analyses were carried out in a fairly good vacuum $\left(<10^{-4}\right.$ Torr for all temperatures, better than $3 \times 10^{-5}$ Torr for $\mathrm{T}>400^{\circ} \mathrm{C}$ ), so redox reactions at high temperatures can safely be ruled out.

Figure 10 shows the variation of $J^{i} / J^{f}$ with $J_{s}(\mathrm{~B})$ and with $J(5 \mathrm{kOe}) / J_{s^{*}} J^{i} / J^{f}$ is the ratio of magnetizations at room temperature in a field of $5 \mathrm{kOe}$ before and after the sample was heated to $700^{\circ} \mathrm{C}$ in vacuum. $J_{s}(\mathrm{~B})$ is the saturation magnetization before heating, extrapolated from the magnetization at $5 \mathrm{kOe}$, measured by a magnetic balance, using the factor $J(5 \mathrm{kOe}) / J_{s}$, which was independently determined by VSM. As shown in the last section, $J_{s}$ can be taken to represent the cooling rate of the rocks, and $J_{s}$ smaller than $1 \mathrm{emu} / \mathrm{g}$ corresponds to quicker cooling rates at which most magnetic minerals are not well crystallized yet or in the SPM or the SD range. If we disregard the titanomaghemite-bearing samples, there seems to be a trend that magnetization increases after heating for samples $J_{s}$ less than $1 \mathrm{emu} / \mathrm{g}$ (Figure 10a). Figure 10b expresses this by a slightly different method. Apart from some low-temperature-oxidized samples, there is a relation that the $J^{i} / J^{f}$ ratio is smaller for smaller values of $J(5 \mathrm{kOe}) / J_{s^{*}}$. The $J^{i} / J^{f}$ ratio is defined at $5 \mathrm{kOe}$ and not at saturation so a smaller $J^{i} / J^{f}$ ratio indicates either a change from free to

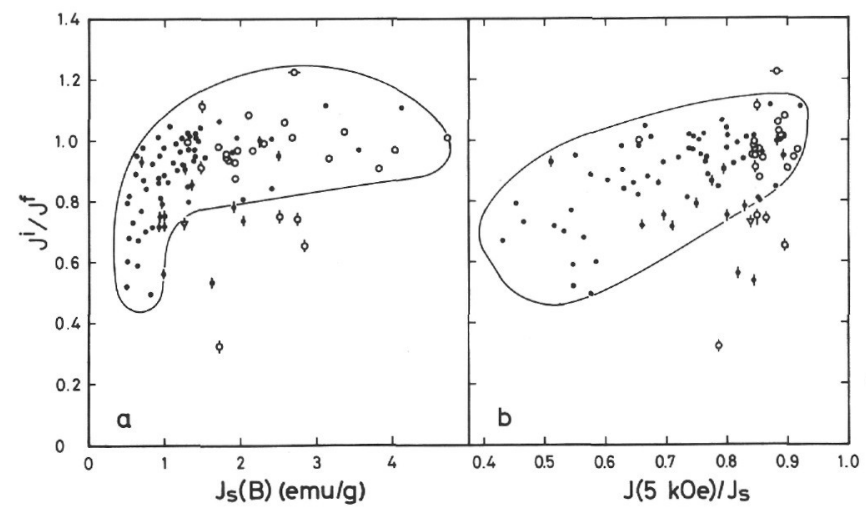

Figure 10. Change in magnetization at $5 \mathrm{kOe}$ caused by

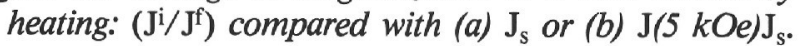
$H T$ samples (including many LT samples) follow trend indicated by the curves, suggesting that the main reason of increase in $\mathrm{J}_{\mathrm{s}}$ in these samples is the growth of ferromagnetic grains.

magnetized state (such as from SPM to SD), or an increase in the amount of ferromagnetic minerals. In any case, we can conclude that the heating had an annealing effect and that the magnetic grains grew during thermomagnetic analysis, with the accompanying change in $J i / J f$. This kind of change is important in experiments where the magnitude of NRM has special meaning, i.e., paleointensity studies. Although such effect has not been reported yet, some of the non-ideal behavior at high temperatures in paleointensity experiments are probably caused by this effect.

\section{CONCLUSIONS}

Many magnetic properties were measured on basalt samples from Holes 430A (Ōjin), 432A (Nintoku), 433A, 433B and 433C (Suiko), drilled on the Emperor Seamount chain. A number of conclusions can be drawn from the individual properties or from interrelations among various properties.

1) The ferromagnetic minerals are titanomagnetites, most of which have undergone high-temperature oxidation. Since high-temperature oxidation is rare in ocean floor basalts, this implies that the basalt lavas erupted subaerially when the seamounts were above sea level.

2) The NRM in these rocks is characterized by moderate intensity $\left(\mathrm{AM}=5.01 \mathrm{emu} / \mathrm{cm}^{3}\right)$, large Konigsberger ratio (9.37), and high stability against AF demagnetization (MDF $=305 \mathrm{Oe})$. As it is certain that the NRM well represents the ambient magnetic field when the rocks formed, these rocks are ideal for studies of paleomagnetism. The major part of a seamount seems to have formed in a relatively short time span of about $1 \mathrm{~m} . \mathrm{y}$. (Dalrymple et al., this volume; Kono, this volume). These facts lend some support for the basic assumptions used in paleomagnetism of seamount magnetic anomalies (uniformity of magnetization, averaging of secular variation, etc.). 
3) The grade of high-temperature oxidation varies from sample to sample, but moderately to highly oxidized samples always have high Curie points, between $500^{\circ} \mathrm{C}$ and $600^{\circ} \mathrm{C}$, suggesting that separation into magnetite solid solution and ilmenite solid solution is almost complete at the moderate stage of high-temperature oxidation.

4) Samples with initial Curie temperatures between $300^{\circ} \mathrm{C}$ and $500^{\circ} \mathrm{C}$ always contain some trace of secondary low-temperature oxidation. High-temperture oxidation in such samples is always low grade.

5) Since it is very unlikely that Curie tempertures between $200^{\circ} \mathrm{C}$ and $500^{\circ} \mathrm{C}$ did not exist among the original basaltic rocks (titanomagnetites with intermediate Curie temperatures are common in basalts of the Hawaii Island), the ferromagnetic minerals with such Curie temperatures were very susceptible to low-temperature oxidation and underwent titanomaghemitization, and/or the parts of lava flows containing such minerals were preferentially lost by erosion, etc. Titanomagnetites which were subjected to high-temperature oxidation may become resistant to low-temperature oxidation.

6) Saturation magnetization is a useful parameter for representing the cooling rate or crystal growth of ferromagnetic minerals. The linear relation between $J_{s}$ and $\chi$ may discriminate the structural differences of ferromagnetic grains as between homogeneous grains, and those subdivided by ilmenite lamellae.

7) Changes in many parameters, such as $J_{r}, J_{r} / J_{s}$, and $J(5 \mathrm{kOe}) / J_{s}$, can be interpreted in terms of change in effective grain size, from SPM, SD, PSD, to MD, as the cooling rate becomes lower. These results show that many of the ferromagnetic minerals in the present samples are in the SD to PSD size range, which perhaps is the reason for the high observed stability of remanence.

8) Heating in vacuum causes a significant increase in magnetization in numerous samples which contain many SPM grains. This is attributable to crystal growth by annealing.

9) Apart from the Curie point, there is no difference between HT samples and LT samples, either in their magnetic properties or in the interrelations of those properties. Therefore, high-temperature oxidation is the dominant process, and low-temperature oxidation did not proceed much or affect magnetic properties in the present basalts.

10) Some systematic differences exist between magnetic properties of tholeiites and those of alkalic basalts. The reason for the difference is not clear at this stage.

\section{ACKNOWLEDGMENTS}

I am grateful to many of the scientific staff on board the Glomar Challenger, and especially to Toshiaki Takayama, for help in sampling of minicores; to Tomosaburo Saito (Geological Survey of Japan) for the use of the Bison susceptibility meter; to Tadashi Nishitani (University of Tokyo) for some of the X-ray data; and to Yozo Hamano (University of Tokyo) for discussions on interpretations of the results. Hysteresis parameters were measured using the vibration sample magnetometer of the Cryogenic Centre, University of Tokyo.

\section{REFERENCES}

Ade-Hall, J. M., Johnson, H. P., and Ryall, O. J. C.,1976. Rock magnetism of basalts, Leg 34. In Yeats, R. S., Hart, S. R., et al., Initial Reports of the Deep Sea Drilling Project, v. 34: Washington (U.S. Government Printing Office), pp. $459-468$.

Ade-Hall, J. M., Khan, M. A., Dagley, P., and Wilson, R. L., 1968. A detailed opaque petrological and magnetic investigation of a single Tertiary lava flow from Skye, Scotland - I. Iron-titanium oxide petrology, Geophys. J. Roy. Astron. Soc., v. 16, pp. 375-388.

Barraclough, D. R. and Fabiano, E. B., 1977. Grid values and charts for the IGRF1975.0, IAGA Bull., No. 38: Paris (IUGG Publ. Office).

Buddington, A. F. and Lindsley, D. H., 1964. Iron-titanium oxide minerals and synthetic equivalents, J. Petrol., v. 5, pp. 310-357.

Dunlop, D. J., 1973. Thermoremanent magnetization in submicroscopic magnetite, J. Geophys. Res., v. 78, pp. 76027613.

Hall, J. M. and Ryall, P. J. C., 1977. Rock magnetism of basement rocks, Leg 37. In Aumento, F., Melson, W. G., et al., Initial Reports of the Deep Sea Drilling Project, v. 37: Washington (U.S. Government Printing Office), pp. 489-501.

Hamano, Y., Nishitani, T., and Kono, M., in press. Magnetic properties of basalt samples from Holes 417D and 418A. In Donnelly, T., Francheteau, J., Bryan, W., Robinson, P., Flower, M., Salisbury, M., et al., Initial Reports of the Deep Sea Drilling Project, v. 51, 52, 53: Washington (U.S. Government Printing Office).

Harrison, C. G. A., 1976. Magnetization of the oceanic crust, Geophys. J. Roy. Astron. Soc., v. 47, p. 257-283.

Johnson, H. P. and Hall, J. M., 1978. A detailed rock magnetic and opaque mineralogy study of the basalts from the Nazca Plate, Geophys. J. Roy. Astron. Soc., v. 52, pp. 45-64.

Kodama, K., Uyeda, S., and Isezaki, N., 1978. Paleomagnetism of Suiko Seamount, Emperor Seamount Chain, Geophys. Res. Lett., v. 5, pp. 165-168.

Lowrie, W., 1974. Oceanic basalt magnetic properties and the Vine and Matthews hypothesis, J. Geophys., v. 40, pp. 513-536.

, 1977. Intensity and direction of magnetization in oceanic basalts, J. Geol. Soc. Lond., v. 133, pp. 61-82.

Marshall, M., 1978. The magnetic properties of some DSDP basalts from the north Pacific and inferences for Pacific plate tectonics, J. Geophys. Res., v. 83, pp. 289-308.

Marshall, M. and Cox, A., 1971. Magnetism of pillow basalts and their petrology, Geol. Soc. Am. Bull., v. 82, pp. 537-552.

Morgan, W. J., 1971. Convection plumes in the lower mantle, Nature, v. 230, pp. 42-43.

1972. Plate motions and deep mantle convection, Geol. Soc. Am. Memoir, v. 132, pp. 7-22.

Ozima, M., Joshima, M., and Kinoshita, H., 1974. Magnetic properties of submarine basalts and the implications on the structure of the oceanic crust, J. Geomag. Geoelectr., v. 26, pp. 335-354.

Ozima, M. and Larson, E. E., 1970. Low- and high-temperature oxidation of titanomagnetite in relation to irreversible changes in the magnetic properties of submarine basalts, J. Geophys. Res., v. 75, pp. 1003-1017.

Ozima, M. and Ozima, M., 1971. Characteristic thermomagnetic curve in submarine basalts, J. Geophys. Res., v. 76, pp. 2051-2056. 
Ozima, M., Ozima, M., and Kaneoka, I., 1968. Potassiumargon ages and magnetic properties of some dredged submarine basalts and their geophysical implications, $J$. Geophys. Res., v. 73, pp. 711-723.

Parry, L. G., 1965. Magnetic properties of dispersed magnetite powders, Phil. Mag., v. 11, pp. 303-312.
Readman, P. W. and O'Reilly, W., 1972. Magnetic properties of oxidized (cation-deficient) titanomagnetites (Fe, Ti, $\square)_{3} \mathrm{O}_{4}$, J. Geomag. Geoelectr., v. 24, pp. 69-90.

Strangway, D. W., Larson, E. E., and Goldstein, M., 1968. A possible cause of high magnetic stability in volcanic rocks, J. Geophys. Res., v. 73, pp. 3787-3795. 